\title{
Seismic Characterization of Basalt Topography at Two Candidate Sites for the INL Remote-Handled Low-Level Waste Disposal Project
}

April 2011

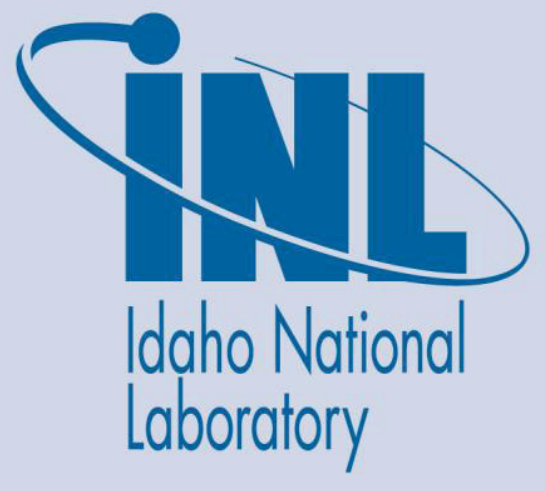

The INL is a U.S. Department of Energy National Laboratory operated by Battelle Energy Alliance 


\section{DISCLAIMER}

This information was prepared as an account of work sponsored by an agency of the U.S. Government. Neither the U.S. Government nor any agency thereof, nor any of their employees, makes any warranty, expressed or implied, or assumes any legal liability or responsibility for the accuracy, completeness, or usefulness, of any information, apparatus, product, or process disclosed, or represents that its use would not infringe privately owned rights. References herein to any specific commercial product, process, or service by trade name, trade mark, manufacturer, or otherwise, does not necessarily constitute or imply its endorsement, recommendation, or favoring by the U.S. Government or any agency thereof. The views and opinions of authors expressed herein do not necessarily state or reflect those of the U.S. Government or any agency thereof. 


\section{Seismic Characterization of Basalt Topography at Two Candidate Sites for the INL Remote-Handled Low- Level Waste Disposal Project}

April 2011

Idaho National Laboratory Idaho Falls, Idaho 83415

http://www.inl.gov

Prepared for the

U.S. Department of Energy

Office of Nuclear Energy

Under DOE Idaho Operations Office

Contract DE-AC07-05ID14517 



\begin{abstract}
This report presents the seismic refraction results from the depth to bed rock surveys for two areas being considered for the Remote-Handled Low-Level Waste (RH-LLW) disposal facility at the Idaho National Laboratory. The first area (Site 5) surveyed is located southwest of the Advanced Test Reactor Complex and the second (Site 34) is located west of Lincoln Boulevard near the southwest corner of the Idaho Nuclear Technology and Engineering Center (INTEC). At Site 5, large area and smaller-scale detailed surveys were performed. At Site 34, a large area survey was performed.

The purpose of the surveys was to define the topography of the interface between the surficial alluvium and underlying basalt. Seismic data were first collected and processed using seismic refraction tomographic inversion. Threedimensional images for both sites were rendered from the data to image the depth and velocities of the subsurface layers. Based on the interpreted top of basalt data at Site 5, a more detailed survey was conducted to refine depth to basalt.

This report briefly covers relevant issues in the collection, processing and inversion of the seismic refraction data and in the imaging process. Included are the parameters for inversion and result rendering and visualization such as the inclusion of physical features. Results from the processing effort presented in this report include fence diagrams of the earth model, for the large area surveys and iso-velocity surfaces and cross sections from the detailed survey.
\end{abstract}




\section{CONTENTS}

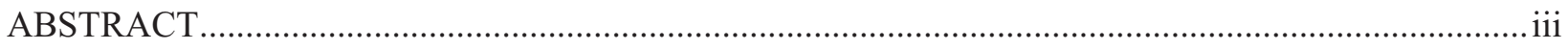

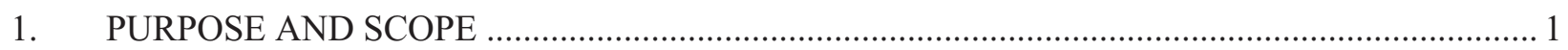

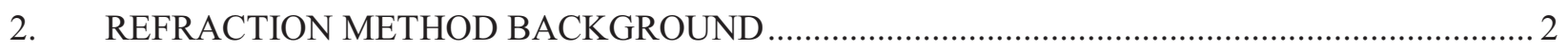

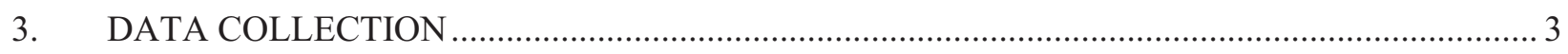

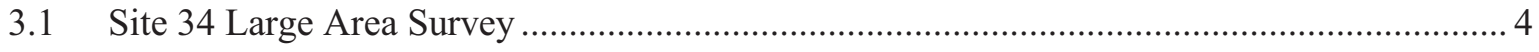

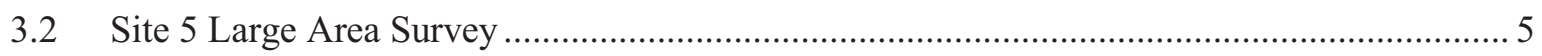

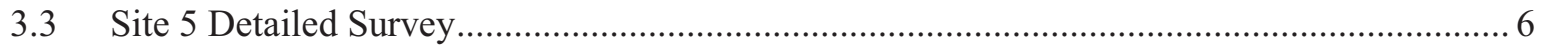

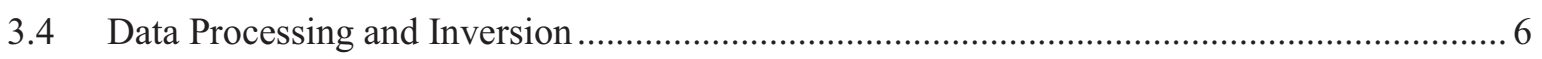

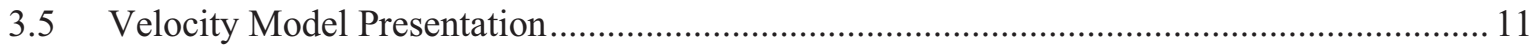

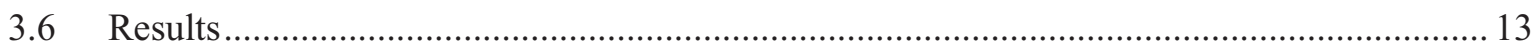

3.6.1 Site 34 Large Area Survey .......................................................................... 13

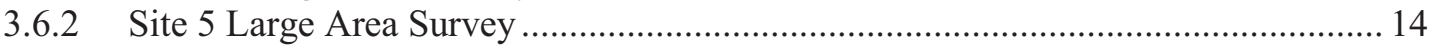

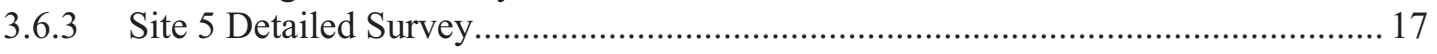

4. COMPARISONS OF SEISMIC RESULTS TO DRILLING DATA …......................................... 19

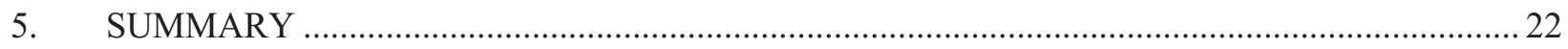

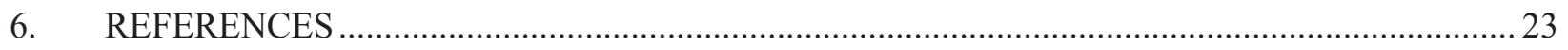

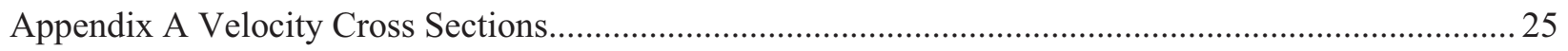

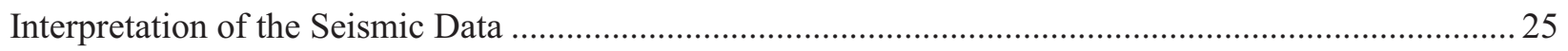

\section{FIGURES}

Figure 1. Locations of surveys conducted to define the top of basalt for the proposed remotehandled low-level waste disposal facility. 2

Figure 2. Example of seismic refraction and interpretation.............................................................. 3

Figure 3. Example seismic recording showing acoustic arrival, layer velocity and resultant depth............ 3

Figure 4. Picture of the PEG-40 accelerated weight drop used as the seismic source in this survey. ......... 4

Figure 5. Site 34 location showing large area survey lines. The inset shows the survey area in relation to the INTEC Facility as well as Lincoln Blvd. The overlying layers in the main figure show the seismic lines (red lines) and shot points (black dots)......

Figure 6. Site 5 location showing large area survey lines. The inset shows the survey area in relation to the ATR Complex. The overlying layers in the main figure show the seismic lines (red lines) and shot points (black dots). 
Figure 7. Map of the Site 5 detailed survey area showing the seismic lines (red lines) and shot points (black dots).

Figure 8. Examples of data in time-distance curve format. The top figure shows the layer picks in red (top layer) and green (lower layer). The lower figure shows the rough shot-point based model derived from the layer picking process.....

Figure 9. This figure shows the initial model parameters (upper left) used to create the initial gridded tomographic model (upper right). The typical inversion parameters in the lower left were optimized at the start of the project and used on each line to start an inversion process that culminated in a final model. The lower right shows the final $\left(50^{\text {th }}\right)$ model iteration output though this is not necessarily the model chosen as the best for any given line.

Figure 10. Screen shot of inversion animation showing developing earth model. The upper left plot shows the fit error between each data derived (picked) and model derived (calculated) time pick value. The upper center shows the root mean square (RMS) curve for all 50 inversions with a circle indicating the current RMS value on the overall curve. The upper right shows the histogram of misfit values and helps indicate deviating solutions. The main middle plot shows the current velocity model and the lower plot shows the vertical derivative of the velocity (possible layer boundaries).

Figure 11: Upper left - Screen shot of EVS flow used to produce surfaces and cross sections. Each line has an individual path. The relative velocity values for each velocity file have been set to equal min and max. Lower left and center right - Screen shots of the kriging parameters used to blend the data and produce the images in this report. The values shown such as Reach (radial distance to include) and Points (maximum number of points to include) were set to be the optimum kriging parameters for adequately smoothing the data while remaining faithful to the features in the original 2-D results.

Figure12. The Site 34, fence diagram of acoustic velocity from land surface to a depth of $40 \mathrm{~m}$ bgs showing the velocity distribution with depth. The lower velocities (blue to green colors) deepen toward the west end of the survey area indicating a deeper sediment section.

Figure 13. Site 34 simplified fence diagram of acoustic velocity from land surface to a depth of $40 \mathrm{~m}$ bgs indicating four layers interpreted from the seismic data. Contours are provided at each depth. The four layers represent: dark blue is top soil, light blue indicates a transition zone, green represents a higher velocity alluvial deposit or weathered bedrock and yellow indicates competent bedrock

Figure 14. Site 5 large area survey fence diagram from $44 \mathrm{ft}$ bgs and deeper from 30 degree elevation, looking North. This shows the velocity distribution with depth near the expected depth of bedrock based on Well TRA-07 which is near the east end of Line 4. This result indicates the lower velocities (green) deepen toward the west end of the survey area. Velocity units are listed incorrectly, units are $\mathrm{Km} / \mathrm{s}$.

Figure 15. Site 5 simplified fence diagram indicating four layers interpreted from the seismic data. Contours represent depth and the four layers: dark blue is top soil, light blue 
indicates a transition zone, green represents a higher velocity alluvial deposit or weathered rubble-ized bedrock and yellow indicates competent bedrock.

Figure 16. Site 5 detailed survey area results shown as screen captures of the iso-velocity surface animation. This process is used to identify the likely surface expression of layer boundaries and aid in interpretation of the results. This figure shows the complete velocity block with blue representing the slower velocities of the overlying sediments (a), the 'melting away' of the overlying sediments (b), revealing a coherent underlying surface (c), and an incoherent velocity picture as noise dominates in the bottom of the section (d).

Figure 17. Site 5 detailed survey area representative of bedrock surface. This image shows a roughly flat surface that dips slightly to the northeast. Most of the smaller-scale variation in the surface seems to be associated with differences in the cross lines.

Figure 18. Site 34, line 1 acoustic velocity. Blue represents top of basalt, grey is an intermediate zone, and yellow represents the alluvium. The depth below land surface is indicated in meters.

Figure 19. Site 34 borehole locations. The boreholes within the blue line are locations with a mismatch between the interpretation of the seismic data and borehole data of more than 3 meters. Line 2 had noisy data on this line and this was most likely a contributing factor to the mismatch at Boreholes S-03 and S-04.

Figure 20. Site 5 borehole locations. The boreholes within the blue line are locations with a mismatch between the seismic data and borehole data of more than 3 meters. The areas of mismatch at this location are most likely a refracting layer above the basalt that could be a clay layer.

Figure A-1. Site 34, line 1 acoustic velocity. Blue represents top of basalt, grey is an intermediate zone, and yellow represents the alluvium. The depth $(\mathrm{ZM})$ below land surface is indicated in meters.

Figure A-2. Site 34, line 2 acoustic velocity. Blue represents top of basalt, grey is an intermediate zone, and yellow represents the alluvium. The depth below land surface is indicated in meters.

Figure A-3. Site 34, line 3 acoustic velocity. Blue represents top of basalt, grey is an intermediate zone, and yellow represents the alluvium. The depth below land surface is indicated in meters.

Figure A-4. Site 34, line 4 acoustic velocity. Blue represents top of basalt, grey is an intermediate zone, and yellow represents the alluvium. The depth below land surface is indicated in meters.

Figure A-5. Site 34, line 5 acoustic velocity. Blue represents top of basalt, grey is an intermediate zone, and yellow represents the alluvium. The depth below land surface is indicated in meters. 
Figure A-6. Site 5, line 1 acoustic velocity. Blue represents top of basalt, grey is an intermediate zone, and yellow represents the alluvium. The depth below land surface is indicated in meters.

Figure A-7. Site 5, line 2 acoustic velocity. Blue represents top of basalt, grey is an intermediate zone, and yellow represents the alluvium. The depth below land surface is indicated in meters.

Figure A-8. Site 5, line 3 acoustic velocity. Blue represents top of basalt, grey is an intermediate zone, and yellow represents the alluvium. The depth below land surface is indicated in meters.

Figure A-9 Site 5, line 4 acoustic velocity. Blue represents top of basalt, grey is an intermediate zone, and yellow represents the alluvium. The depth below land surface is indicated in meters.

Figure A-10. Site 5, line 5 acoustic velocity. Blue represents top of basalt, grey is an intermediate zone, and yellow represents the alluvium. The depth below land surface $(Z)$ is indicated in meters.

Figure A-11. Site 5, line 6 acoustic velocity. Blue represents top of basalt, grey is an intermediate zone, and yellow represents the alluvium. The depth below land surface is indicated in meters.

Figure A-12. Site 5, line 7 acoustic velocity. Blue represents top of basalt, grey is an intermediate zone, and yellow represents the alluvium. The depth below land surface is indicated in meters.

\section{TABLES}

Table 1. A Comparison of basalt depth between borehole data and the seismic survey, data with negative numbers indicating deeper Basalt estimation in the seismic results than found while drilling..... 


\section{Seismic Characterization of Basalt Topography at Two Candidate Sites for the INL Remote-Handled Low-Level Waste Disposal Project}

\section{PURPOSE AND SCOPE}

This report presents the depth to top of basalt determined from seismic surveys for two areas being considered for the Remote-Handled Low-Level Waste (RH-LLW) disposal facility at the Idaho National Laboratory (INL 2011). The first area (Site 5) is located southwest of the Advanced Test Reactor (ATR) Complex and the second site (Site 34) is located west of Lincoln Boulevard near the southwest corner of the Idaho Nuclear Technology and Engineering Center (INTEC) (Figure 1). The purpose of the surveys was to define the topography of the first basalt layer and determine the thickness of the overlying fill to determine if there is adequate depth for the facility at either site.

At the request of the RH-LLW project, INL geophysicists in the Environmental Engineering \& Technology group collected the seismic data in the proposed areas and processed the geophysical data using refraction tomographic inversion. Three-dimensional images were rendered from the data to image the depth and acoustic velocities of the subsurface layers. In this case the alluvium/bedrock interface was the target for this survey.

This report briefly covers relevant issues in the collection, processing and inversion of the seismic refraction data and in the imaging process. Included are the parameters for inversion and result rendering and visualization such as the inclusion of physical features. Results from the processing effort presented in this report include fence diagrams of the earth model for large area surveys of both sites, and isovelocity surfaces and cross sections from a detailed survey of a smaller area within Site 5. 


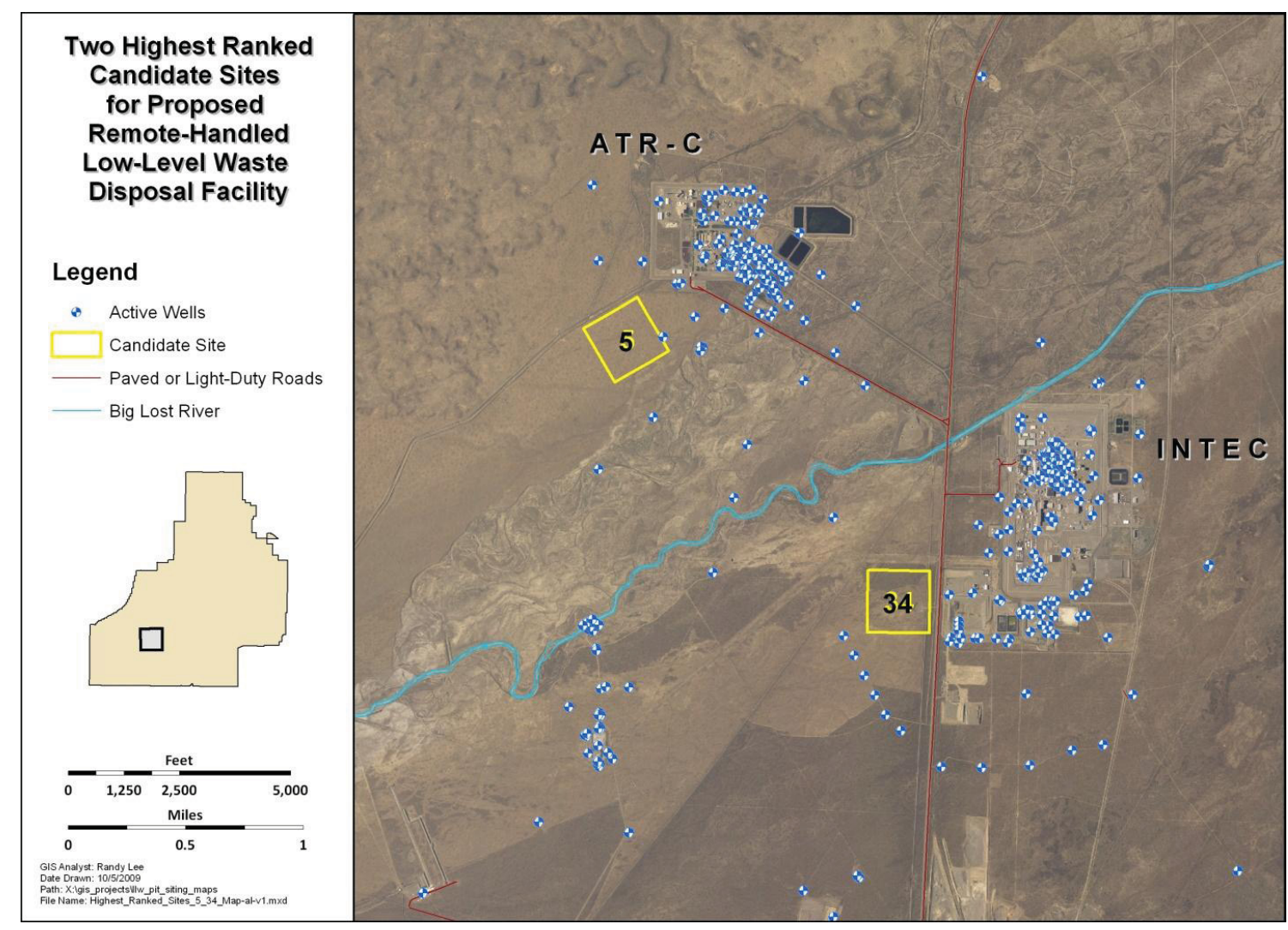

Figure 1. Locations of surveys conducted to define the top of basalt for the proposed remote-handled lowlevel waste disposal facility.

\section{REFRACTION METHOD BACKGROUND}

Seismic refraction is a geophysical acoustical method that uses the initial P-wave (compressive wave) arrival to define the layered structure of the earth. Seismic refraction is one of the most commonly used methods to determine bedrock depths, especially for depths of less than $30 \mathrm{~m}$. The method requires a seismic energy source, usually a sledgehammer is used to determine top of bedrock for alluvium depths of $15 \mathrm{~m}$ or less, and a mechanical source is used for depths to $30 \mathrm{~m}$. The seismic waves produced at a location (shot point) by the energy source penetrate the overburden and refract along the bedrock surface. The refraction method relies on the bending or refracting of acoustic waves at an interface between two media having different acoustic velocities (Snell's Law). Given that the acoustic energy radiates spherically into the media, circularly in a 2-D plane, and the velocity is greater in the lower level, the incident wave will impact the lower layer at a critical angle allowing the energy to travel along the layer interface. The energy radiated back from the layer boundary is recorded at the surface (Figure 2). 


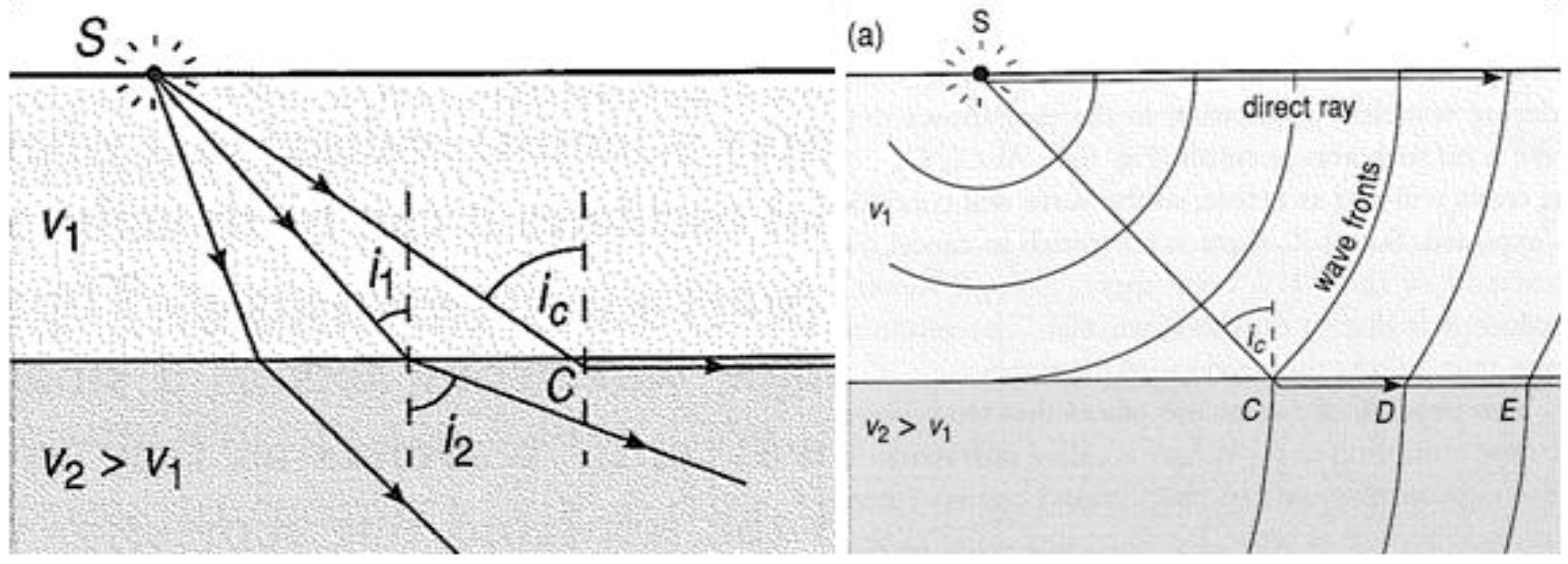

Figure 2. Example of seismic refraction and interpretation.

The resulting seismic data is then inspected and analyzed for to determine the initial arriving energy (first breaks or picks) (Figure 3). This time data is then used to recover the layer thicknesses and velocities. The Refraction method works well where the underlying assumptions are valid including an essentially layered earth (velocity structure) with e layer velocity increasing with depth. Where multiple layers are present, the layer interfaces may be hidden. This can also occur if individual layers are too thin or if the acoustic velocity in the lower bounding layer is much faster than the overlying media.

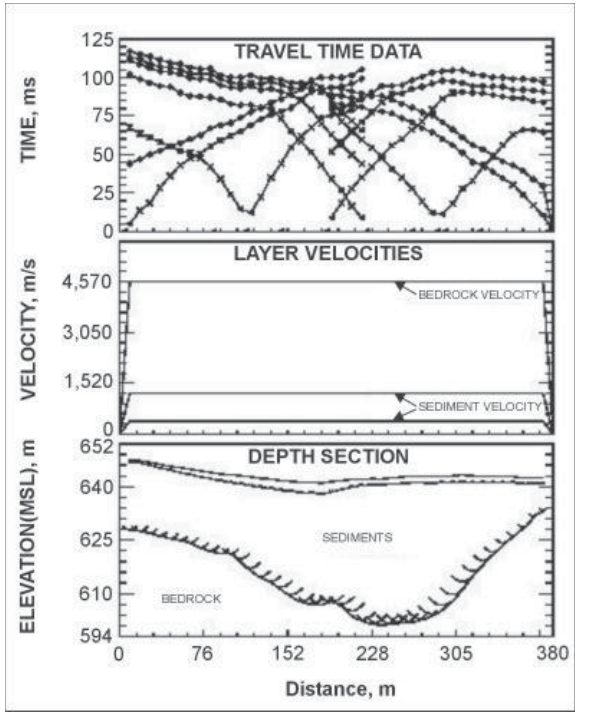

Figure 3. Example seismic recording showing acoustic arrival, layer velocity and resultant depth.

\section{DATA COLLECTION}

Seismic data was collected at the two planned areas between July and November of 2010. A system employing two networked 24-channel Geometrics Geode recording systems, controlled from a laptop, was used to collect data. The data was received from up to forty eight $40-\mathrm{Hz}$ geophones spaced at 3 meters which produced spreads of 141 meters along a seismic line segment. Two to five spreads were used to produce a complete seismic refraction line with the segments overlapped by eight geophones (21 $\mathrm{m})$. A trace length of 0.25 seconds, a sampling frequency of $32 \mathrm{KHz}$ was used to collect the data with digital anti-aliasing filters as the only acquisition filters. 
A PEG-40 accelerated weight drop, mounted on an ATV (Figure 4) was used as the seismic source. And source points were spaced three to four geophones (9-12 $\mathrm{m}$ ) along the spread for a typical 16 shot points per spread. The data at each shot point was stacked (averaged) over fifteen to forty shots to eliminate noise and improve the desired initial arrival signal. Each shot point was surveyed with a Trimble Geo-XT or Geo-XH and post processed to a general accuracy of 1/2 meter.

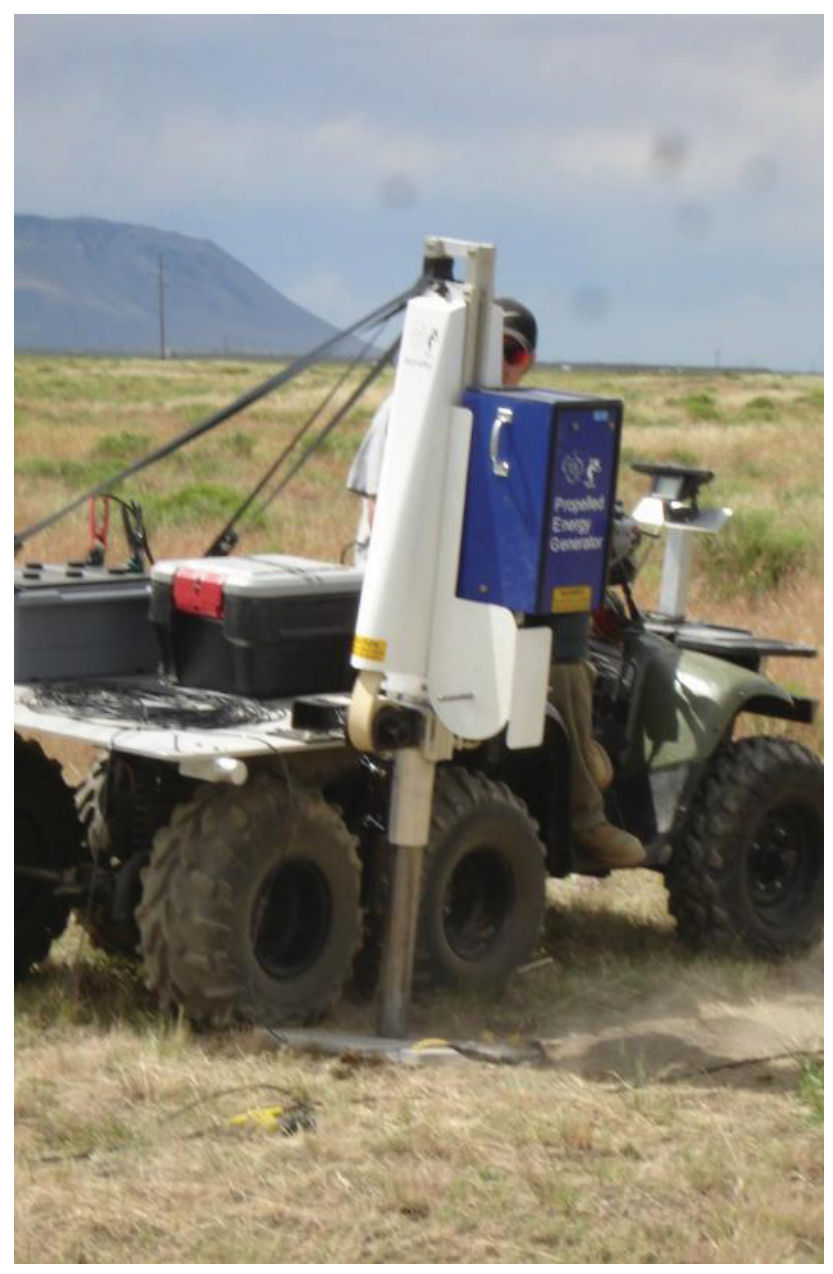

Figure 4. Picture of the PEG-40 accelerated weight drop used as the seismic source in this survey.

\subsection{Site 34 Large Area Survey}

The Site 34 large area survey included five seismic refraction lines. Four parallel lines trending northeast to southwest (sub-parallel to Lincoln Blvd.), and one perpendicular cross line 500 meters long were used with each line consisting of four spreads (Figure 5). Prior to data collection the planned seismic lines were mowed to reduce the anticipated wind noise. Data collection initially proceeded slowly due to traffic noise from the nearby road and pit operations occurring in the Idaho CERCLA Disposal Facility. Later the decision was made to collect data on non-working Fridays and weekends as much as possible which resulted in cleaner data with substantially faster collection rates. The number of shot points per spread was 16 for a total of 64 per line. 


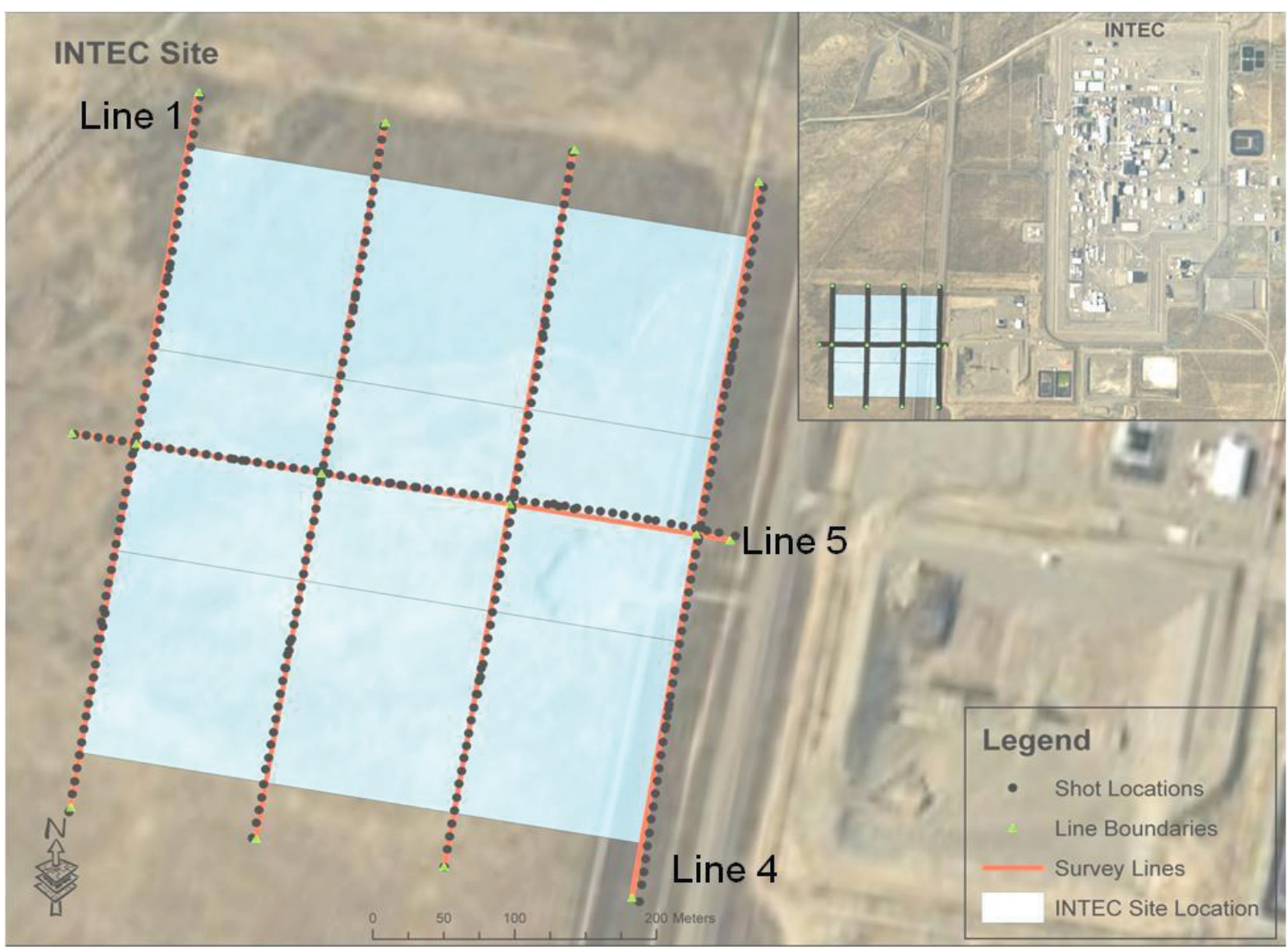

Figure 5. Site 34 location showing large area survey lines. The inset shows the survey area in relation to the INTEC Facility as well as Lincoln Blvd. The overlying layers in the main figure show the seismic lines (red lines) and shot points (black dots).

\subsection{Site 5 Large Area Survey}

The Site 5 large area survey, southwest of the ATR complex, is shown in Figure 6. The survey included five total refraction lines with four parallel lines trending southwest to northeast and one perpendicular cross line. As shown, the closest line is only a few hundred meters from the ATR Parking Lot. The lines were 500 meters long and the parallel lines were spaced 150 meters apart. Each line was collected in 4 overlapping spreads. Shot points were initially spaced every four geophones for 12 shot points per spread or 48 per line. After the first line was collected, it was apparent that wind noise was an issue and all remaining lines were mowed to reduce the effect of the windblown vegetation. Shot point spacing was also reduced to three geophones on average, for a total of 16 shots per spread (64 shots per line). This enabled adequate spatial coverage and data redundancy for tomographic inversion and limited the effect of noisy data in the results through averaging. 


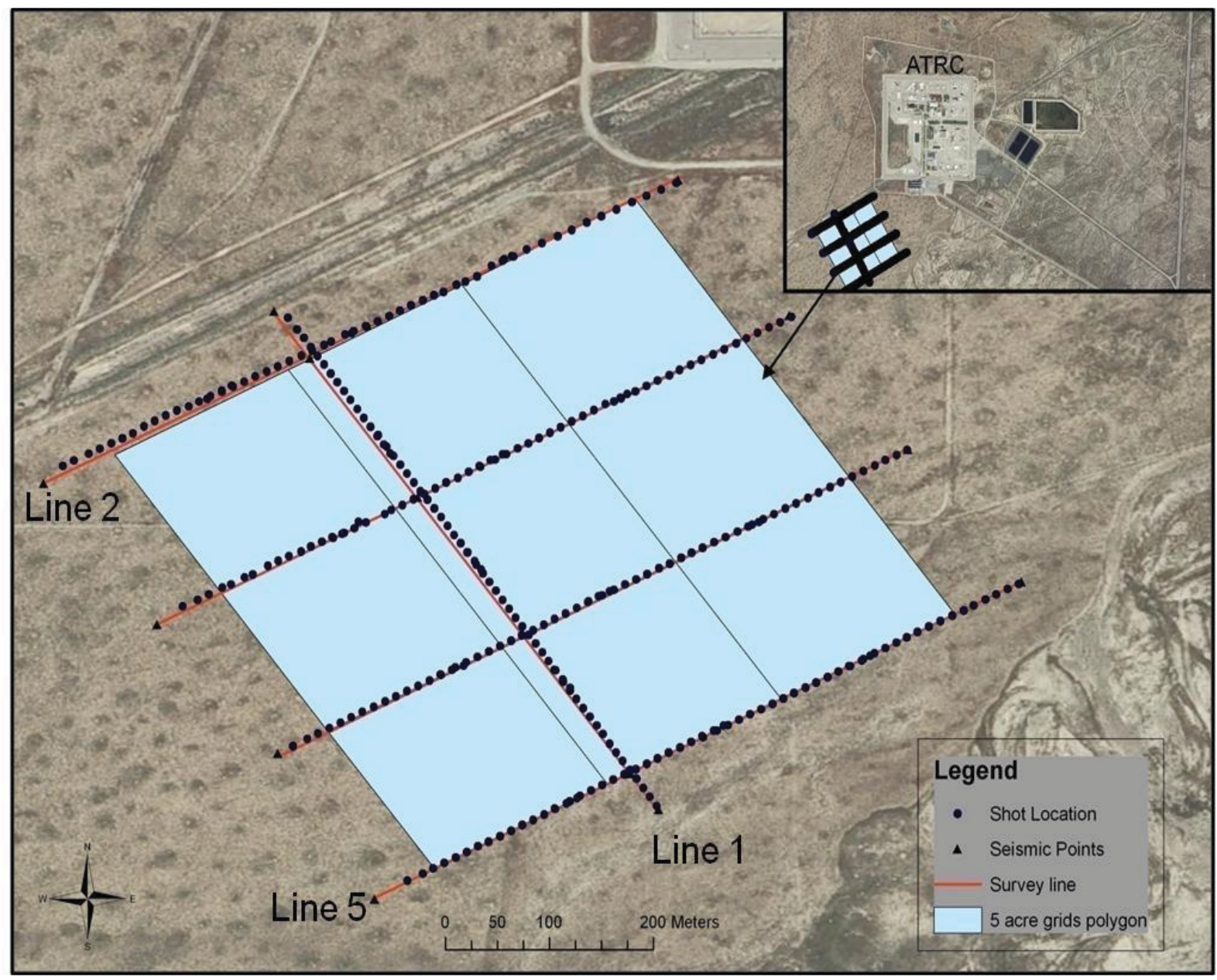

Figure 6. Site 5 location showing large area survey lines. The inset shows the survey area in relation to the ATR Complex. The overlying layers in the main figure show the seismic lines (red lines) and shot points (black dots).

\subsection{Site 5 Detailed Survey}

After the processing and interpretation of the large areas survey at Site 5, a decision was made to perform a higher resolution survey in the most likely area of acceptable depth to bedrock. Figure 7 shows the layout of the Site 5 detailed survey. This included eleven lines with 7 main lines oriented roughly east-west, spaced 30 meters apart, and four perpendicular cross lines spaced 60 meters apart. The primary east-west lines were 380 meters long and consisted of three overlapping spreads. The cross lines were 260 meters long evenly spaced along the east-west lines and consisted of two spreads each. In preparation for work in this smaller detailed area the entire planned survey area was mowed to reduce anticipated wind noise and to facilitate the field work. Shot parameters and geophone spacing were kept the same as the large area survey to enable the inclusion of the earlier data if required.

Figure 7. Map of the Site 5 detailed survey area showing the seismic lines (red lines) and shot points (black dots).

\subsection{Data Processing and Inversion}

Processing and inversion of the seismic refraction data consisted of several steps, including: 
- Standard refraction pre-processing and seismic data and geometry checking for quality assurance/quality control (QA/QC).

- First break (initial energy) time picking and layer assignment.

- Tomographic inversion of time picked data to produce an ideal earth model (velocity structure).

- Post inversion analysis to define the optimal earth model.

The QA/QC check included a verification of the shot and geophone geometry between the data and field notes, and a visual check of the raw data to confirm correct shot positioning based on where the earliest arrivals occurred. Processing continued with first-break (initial energy arrival) picking using a standard vendor supplied program, Pickwin $95 \AA$. This step identifies the arrival of the initial energy, from the shot, at each sensor (geophone) for later use in the inversion process. These first-break arrivals were checked for noise level and intra-shot consistency using another standard vendor supplied program, called Plotrefa ${ }^{\circledR}$. In several cases, it was necessary to reopen the data in the Pickwin95 program, reevaluate the first arrivals, and then repick some of the arrivals to improve the quality of the time distance curve.

Following the pre-processing and first-break time picking, the files containing the first break picks (time-distance curves) were loaded into the Plotrefa ${ }^{\circledR}$ program and two distinct layers were assigned to the velocity trends in the time difference curves. Two layers were chosen because (1) most of the timedistance curves indicated a two-layer or three-layer system was appropriate, and (2) earlier studies performed on similar refraction studies indicated little difference in the final tomographic model produced by two and three layer initial models as long as sufficient iterations were performed. These two layers corresponded to the lower-velocity surface sediments within the rock column and the underlying highervelocity bedrock basalts. The layer picks and time distance curves were then used in a simple shot-point based time-term inversion scheme to create a rough two-layer earth model corresponding to the two distinct velocity trends identified earlier. This process is shown in Figure 8.

The rough shot-point two-layer model was used as the input in the creation of the initial gridded tomographic model. Essentially, this involved superimposing the tomographic grid over the two-layer model and assigning initial velocities to the cells of the tomographic grid based on where the cells occur within the two distinct model velocities. Finally, the tomographic inversion parameters were selected and the inversion performed (Figure 9).

The post-inversion analysis consisted of creating an animation of the inversion iterations (1-50) and a visual analysis of the time-slices to determine when convergence was achieved (Figure 10). For the analysis of the INL seismic refraction data, convergence was defined by:

- The behavior of the root mean square (RMS) convergence curve (e.g. when did it flatten out).

- The overall fit of modeled first arrival times to the picked times (e.g. the point by point data to model differences).

- The overall error distribution (Gaussian or not, extent of outliers).

- Observing changes in the developing earth model.

The point of convergence was selected where the RMS was low, changing little and still decreasing (i.e. no diverging solution), overall fit was good and stable, the distribution shows a near Gaussian curve with no outliers, and where the developing earth model has stabilized (velocity profiles and layers stopped changing). This was generally between iteration 20 and 30 depending on the survey. 


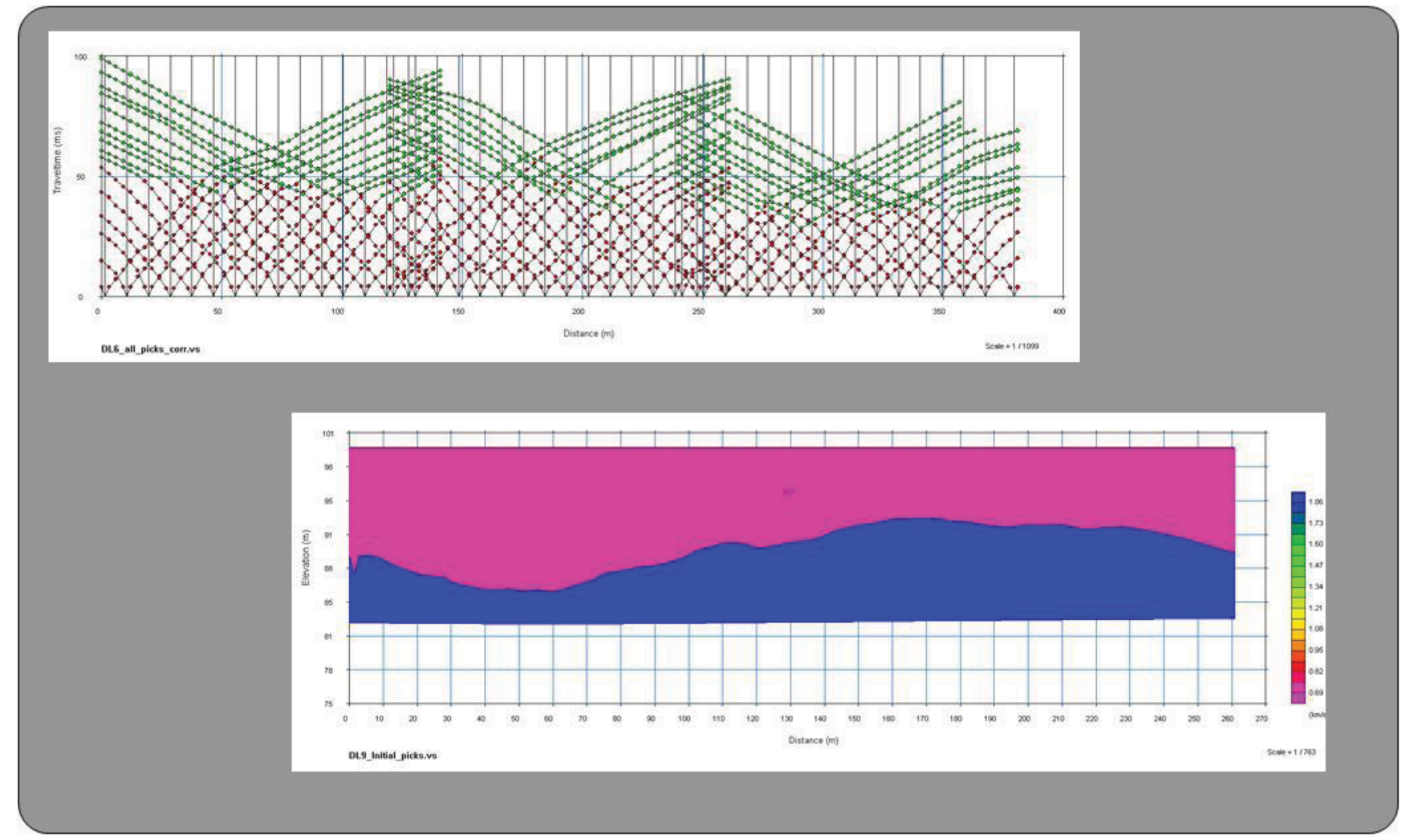

Figure 8. Examples of data in time-distance curve format. The top figure shows the layer picks in red (top layer) and green (lower layer). The lower figure shows the rough shot-point based model derived from the layer picking process. 


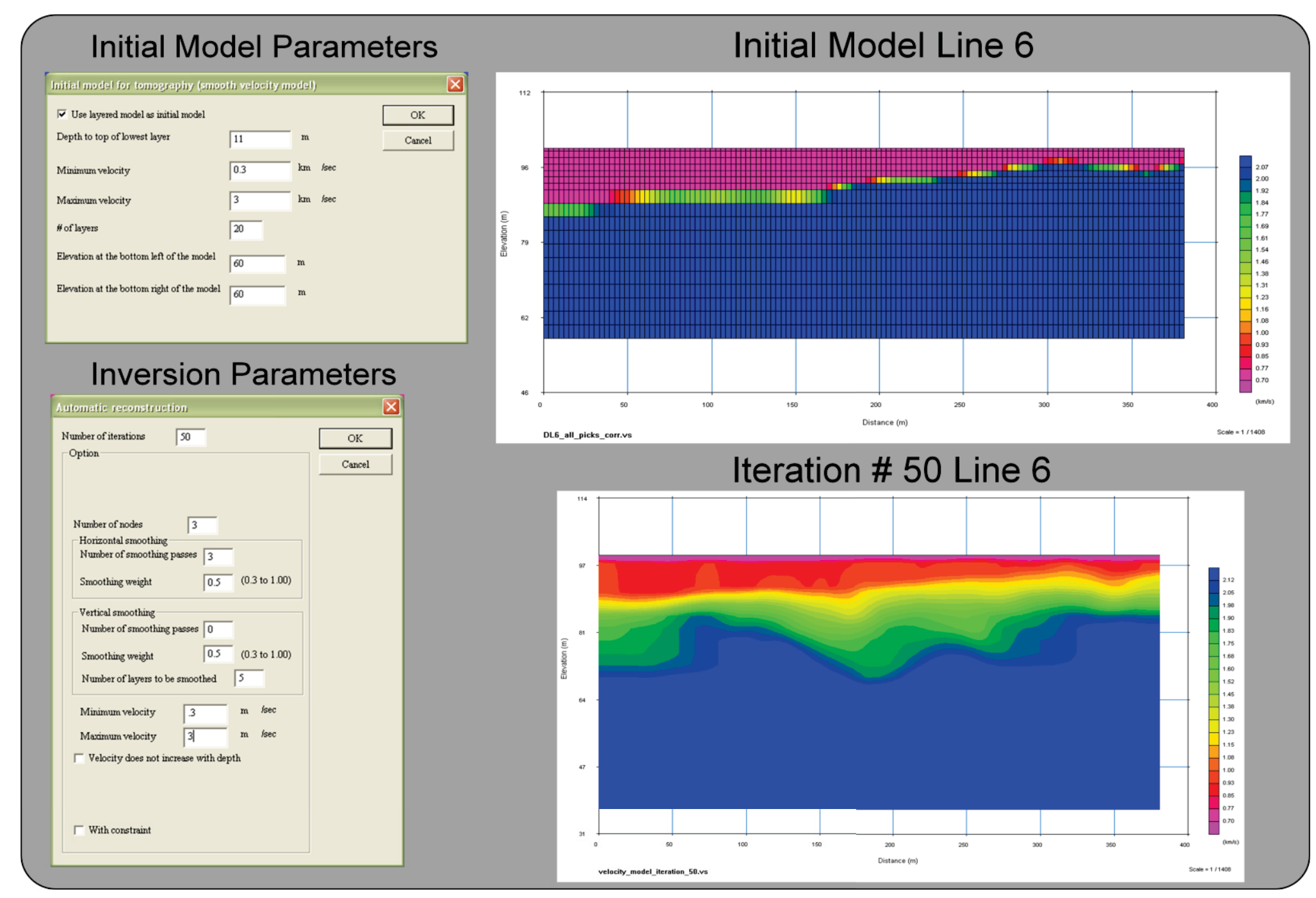

Figure 9. This figure shows the initial model parameters (upper left) used to create the initial gridded tomographic model (upper right). The typical inversion parameters in the lower left were optimized at the start of the project and used on each line to start an inversion process that culminated in a final model. The lower right shows the final $\left(50^{\text {th }}\right)$ model iteration output though this is not necessarily the model chosen as the best for any given line. 


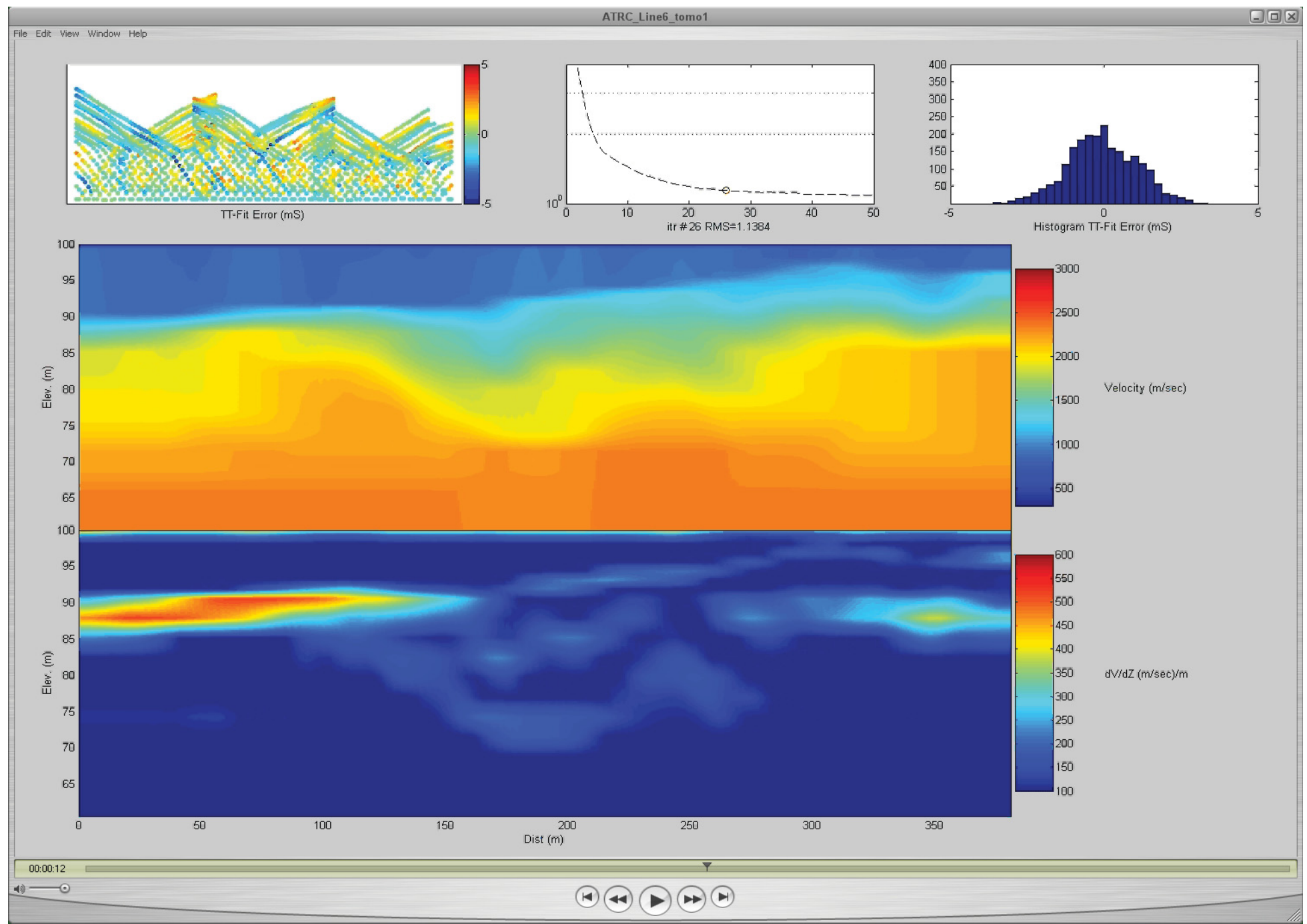

Figure 10. Screen shot of inversion animation showing developing earth model. The upper left plot shows the fit error between each data derived (picked) and model derived (calculated) time pick value. The upper center shows the root mean square (RMS) curve for all 50 inversions with a circle indicating the current RMS value on the overall curve. The upper right shows the histogram of misfit values and helps indicate deviating solutions. The main middle plot shows the current velocity model and the lower plot shows the vertical derivative of the velocity (possible layer boundaries). 


\subsection{Velocity Model Presentation}

Following the processing and inversion of the seismic refraction data to develop the best fit earth model for each individual line, the chosen inversion iteration from each line was grouped and input files created for imaging in the Environmental Visualization System (EVS) ${ }^{\circledR}$ program. EVS is a standard visualization program that is commonly used in developing visual renderings of geologic data. This imaging effort is aimed at producing 3-D renderings, in this case of velocity layers, from the grid of 2-D profiles. The process required several files: (1) a geology file consisting of the tomographic grid (layer geometry) for all lines, (2) a velocity file consisting of the velocity matrix formed from all lines, and (3) a variety of ASCII and AutoCAD DXF files to plot line and geophone positions as well as physical features over the results. The geology and velocity files were created by an in-house MatLab code written at INL, and the survey position file was created in Arc (a GIS software package) from differential GPS surveying of the shot points.

In the EVS flow, the geology and velocity data were kriged and the output saved as an EVS field. Kriging is a statistical regression technique used to interpolate data, in this case seismic velocity results from the processing/inversion process. The technique takes into account spatial dependence (weighting) between data points. Parameters for rendering are given in Figure 11.

The resulting EVS field was then read into the imaging flow, plotted and then saved as a PNG image file. To help indicate relative position of features in the iso-surfaces, the location of Well TRA-07 was shown in the EVS images top view image. The resulting images are plotted top down in perspective and the seismic lines placed as close to the surface as possible to limit parallax issues. 


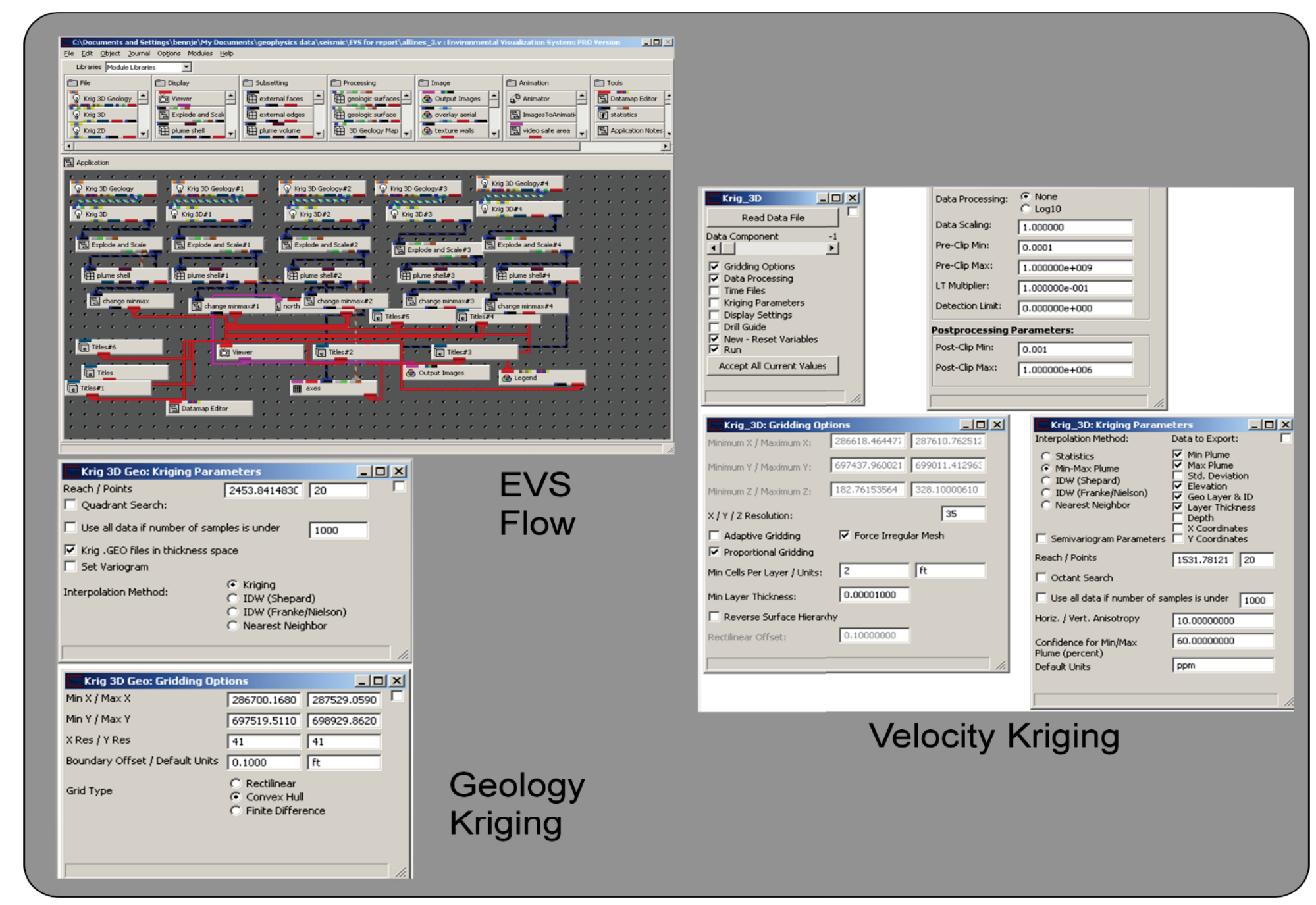

Figure 11: Upper left - Screen shot of EVS flow used to produce surfaces and cross sections. Each line has an individual path. The relative velocity values for each velocity file have been set to equal min and max. Lower left and center right - Screen shots of the kriging parameters used to blend the data and produce the images in this report. The values shown such as Reach (radial distance to include) and Points (maximum number of points to include) were set to be the optimum kriging parameters for adequately smoothing the data while remaining faithful to the features in the original 2-D results. 


\subsection{Results}

\subsubsection{Site 34 Large Area Survey}

The results from the large area at Site 34 could not be credibly kriged into a surface due to the large distance between lines $(150 \mathrm{~m})$ vs. the observed spatial variance in the data (10's of meters). Therefore the results are presented as fence diagrams with velocity color contours at depth. Rendering of the resulting velocity field at Site 34 is shown in Figure 12.

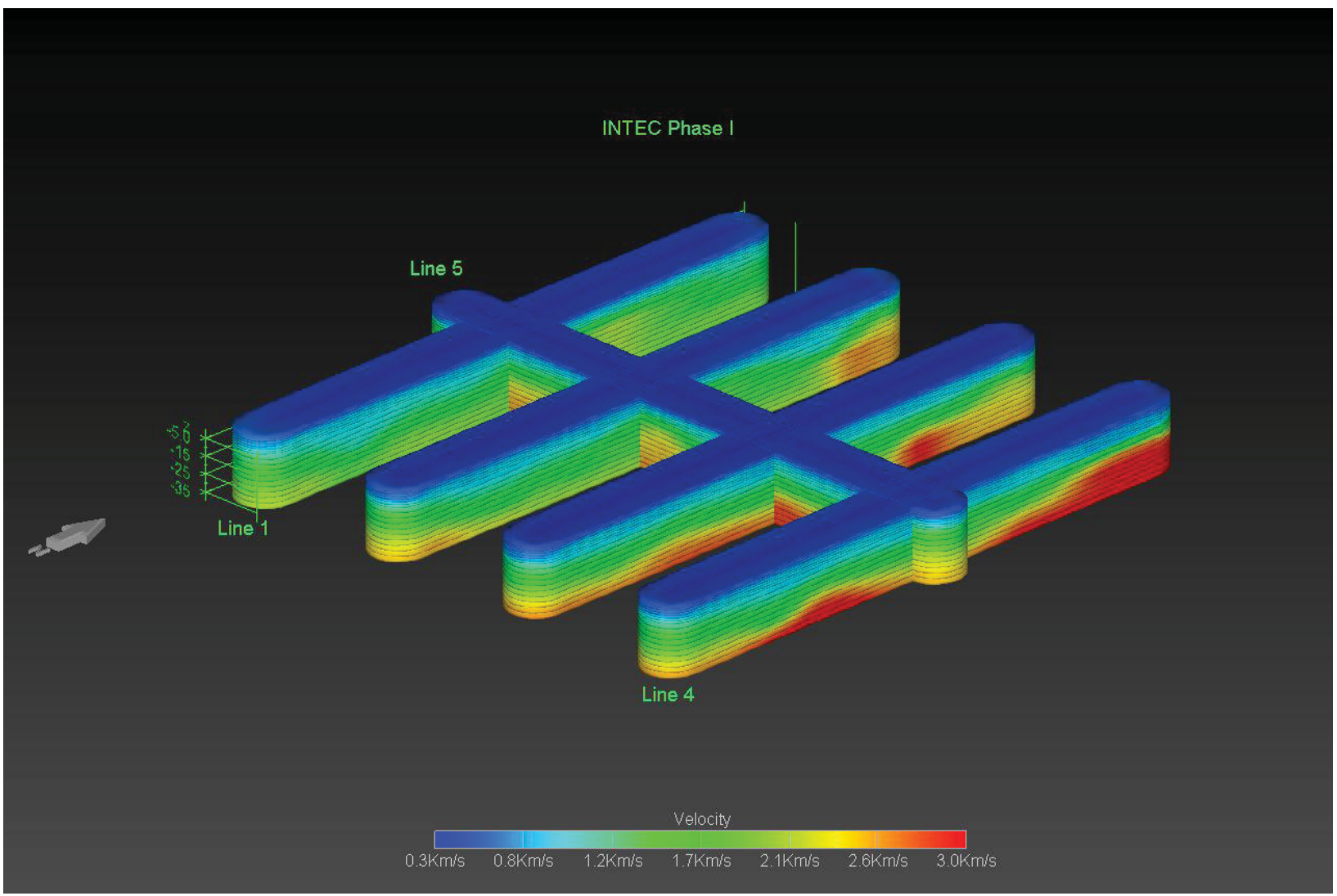

Figure12. The Site 34, fence diagram of acoustic velocity from land surface to a depth of $40 \mathrm{~m}$ bgs showing the velocity distribution with depth. The lower velocities (blue to green colors) deepen toward the west end of the survey area indicating a deeper sediment section.

Figure 13 shows the geologic section interpreted from the inverted velocity given in Figure 12. This fence diagram shows four possible layers could exist based on the velocity. The four layers represent, from top to bottom, a low velocity soil layer with velocities below $1 \mathrm{Km} / \mathrm{s}$ (dark blue), a layer of gravels/cobbles from $1 \mathrm{Km} / \mathrm{s}$ to $1.6 \mathrm{Km} / \mathrm{s}$ (light blue), blending into a transition zone of gravels or noncompetent basalt from 1.6 to $2.2 \mathrm{Km} / \mathrm{s}$ (green), and finally competent basalt above $2.2 \mathrm{Km} / \mathrm{s}$ (yellow). 


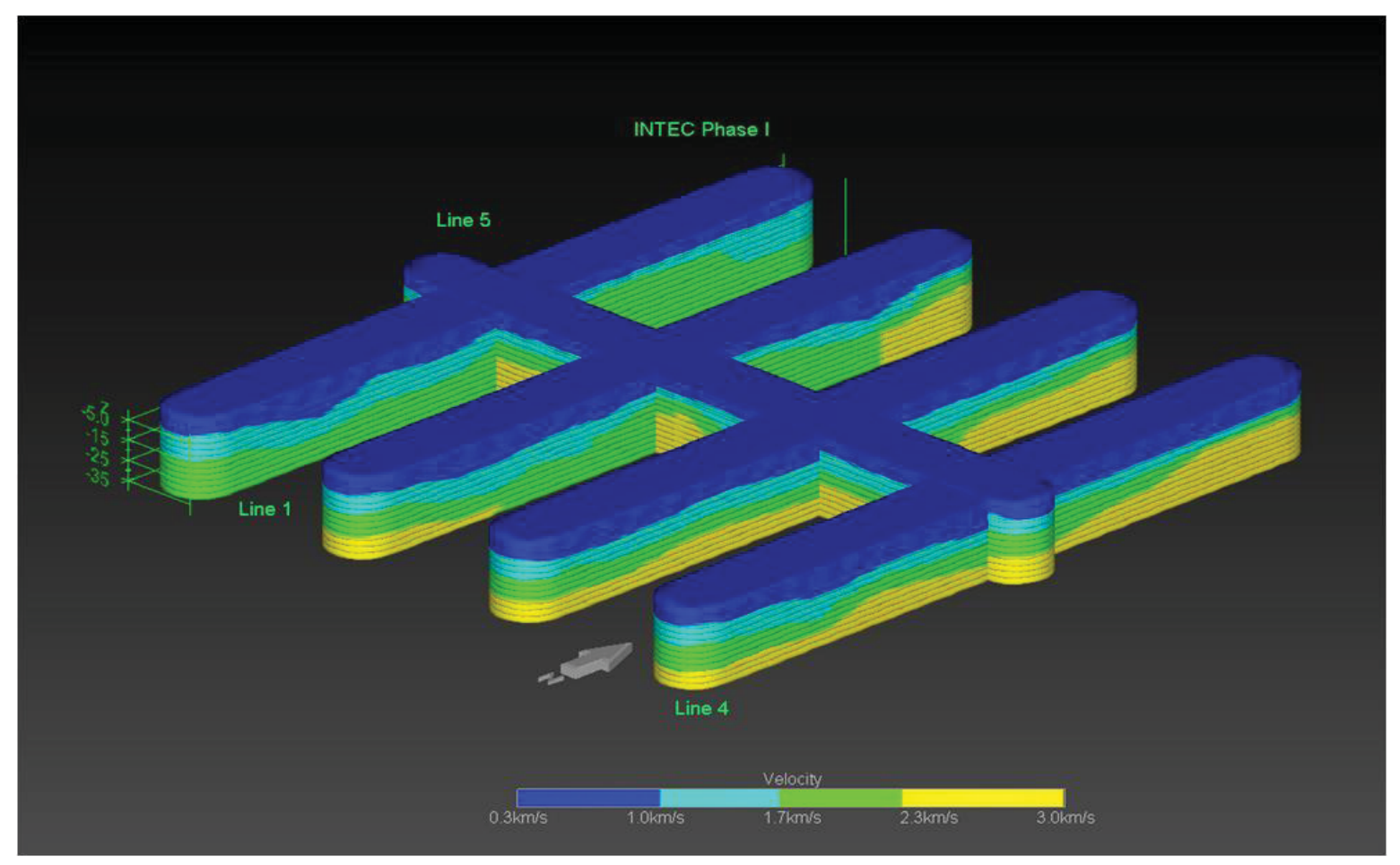

Figure 13. Site 34 simplified fence diagram of acoustic velocity from land surface to a depth of $40 \mathrm{~m}$ bgs indicating four layers interpreted from the seismic data. Contours are provided at each depth. The four layers represent: dark blue is top soil, light blue indicates a transition zone, green represents a higher velocity alluvial deposit or weathered bedrock and yellow indicates competent bedrock.

\subsubsection{Site 5 Large Area Survey}

The results from the large area at Site 5 also could not be credibly kriged into a surface due to the large distance between lines $(150 \mathrm{~m})$ vs. the observed spatial variance in the data (10's of meters). Therefore, the results are also presented as fence diagrams with velocity color contours at depth in Figure 14. Using a nearby well (TRA-07) for ground truth where the alluvial-basalt transition is at 42 feet, the corresponding velocities representing this transition are $1.1 \mathrm{Km} / \mathrm{s}$ to $1.9 \mathrm{Km} / \mathrm{s}$. Figure 14 shows the results at Site 5 beginning 44 feet below ground surface (bgs). This shows the velocity distribution with depth near the expected depth of bedrock based on Well TRA-07 near the east end of Line 4.

The velocity shown in Figure 14 is unusually low for basalt (typically $3-5 \mathrm{Km} / \mathrm{s}$ ) and indicates either an anomalous velocity structure within the basalt, or possibly a lack of energy interacting with the bedrock surface, resulting in an anomalous velocity due to signal to noise issues. This lack of energy could be due to a large velocity contrast above (gravels vs. alluvial sands and silts).

The simplified fence diagram in Figure 15 shows that there are also four possible layers interpreted from the seismic results. These four layers represent, from top to bottom, A low velocity soil layer with velocities below $1 \mathrm{Km} / \mathrm{s}$ (dark blue), a layer of gravels or cobbles from $1 \mathrm{Km} / \mathrm{s}$ to $1.6 \mathrm{Km} / \mathrm{s}$ (light blue) blending into a transition zone of gravels or non-competent basalt from 1.6 to $2.2 \mathrm{Km} / \mathrm{s}$ (green) and finally competent basalt above $2.2 \mathrm{Km} / \mathrm{s}$ (yellow). Based on this interpretation it was proposed the best area to investigate for the future disposal facility is in the central western half of the larger surveyed area because of the potential for thicker alluvial sediments. 


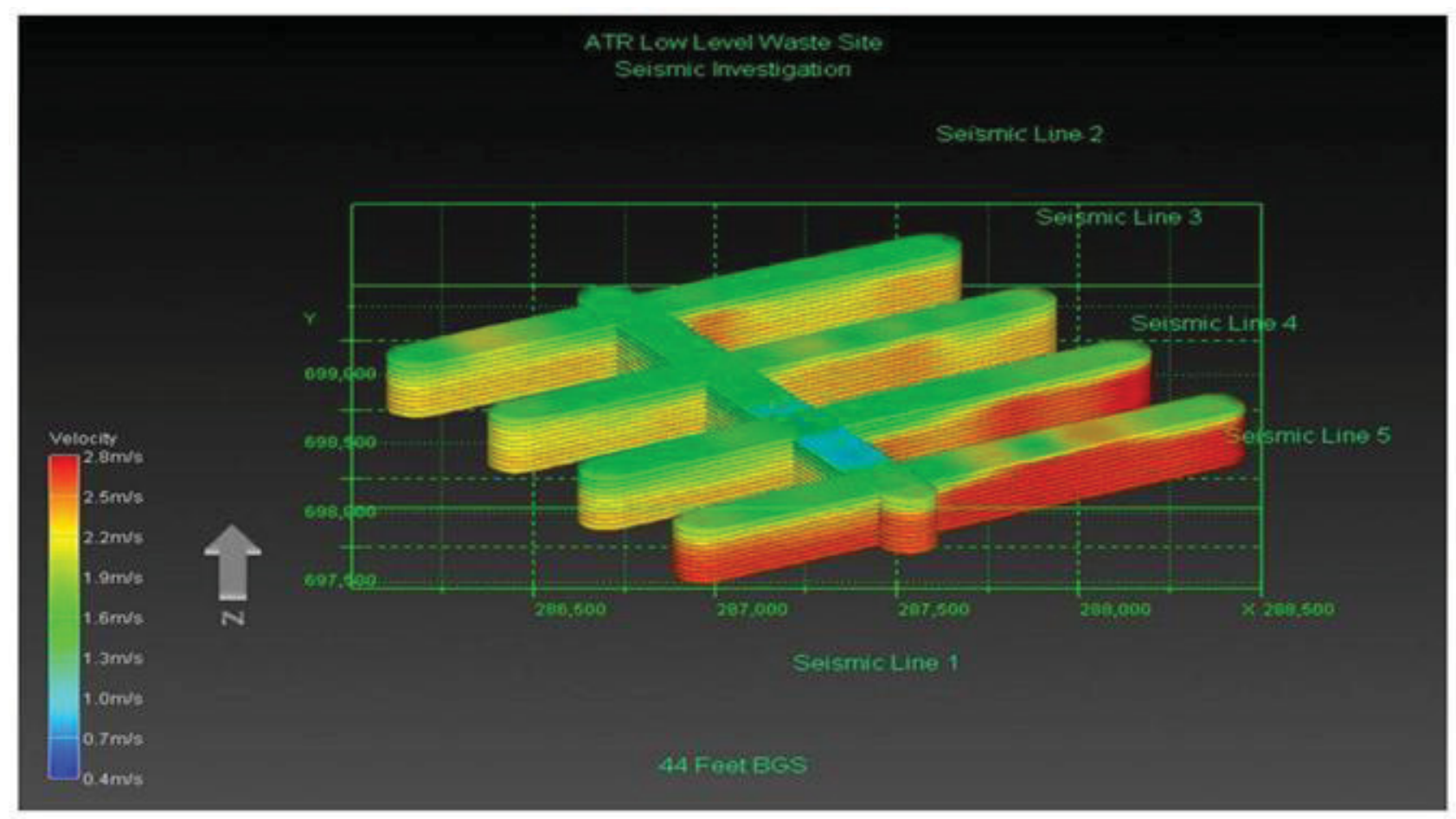

Figure 14. Site 5 large area survey fence diagram from $44 \mathrm{ft}$ bgs and deeper from 30 degree elevation, looking North. This shows the velocity distribution with depth near the expected depth of bedrock based on Well TRA-07 which is near the east end of Line 4. This result indicates the lower velocities (green) deepen toward the west end of the survey area. Velocity units are listed incorrectly, units are Km/s. 


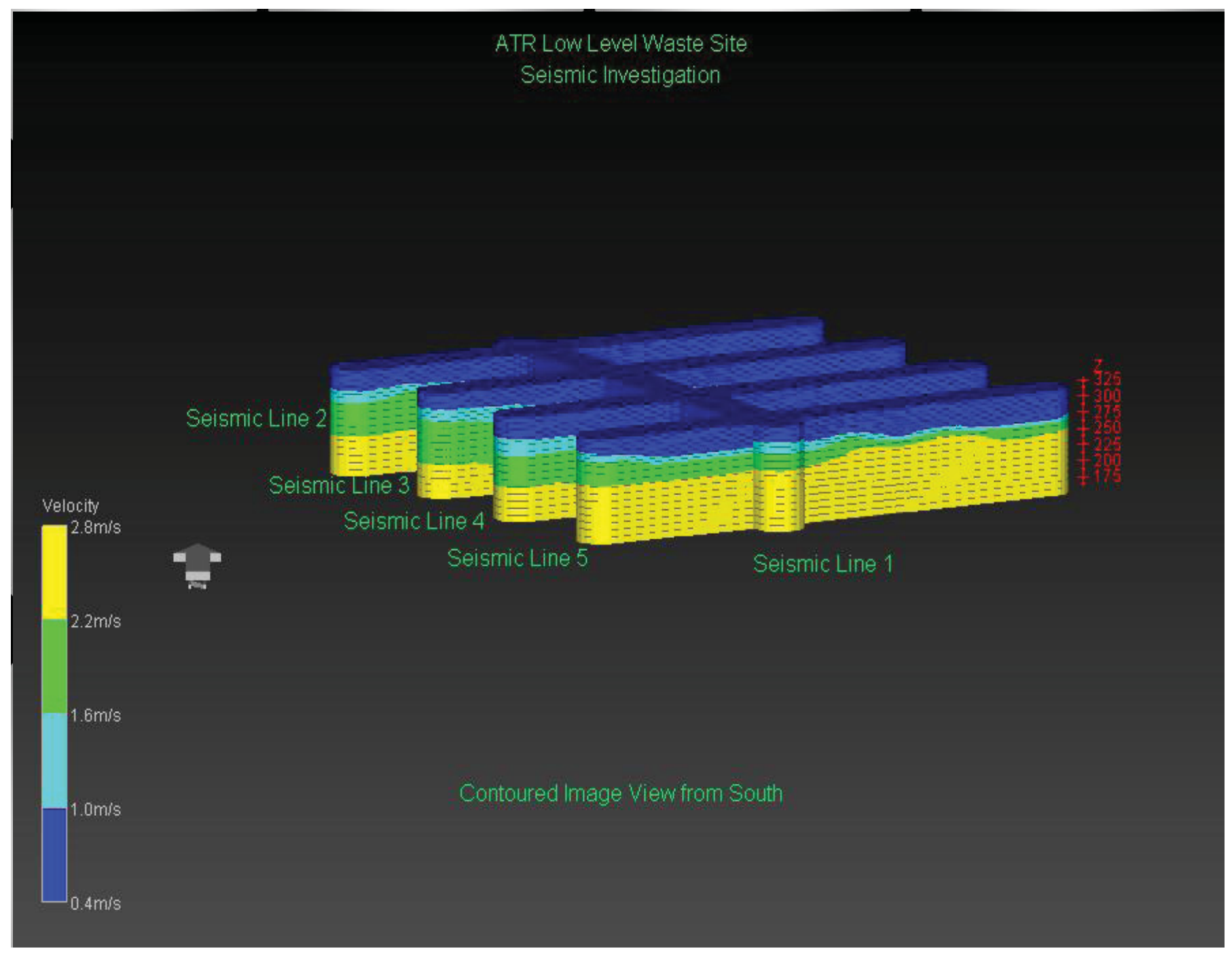

Figure 15. Site 5 simplified fence diagram indicating four layers interpreted from the seismic data. Contours represent depth and the four layers: dark blue is top soil, light blue indicates a transition zone, green represents a higher velocity alluvial deposit or weathered rubble-ized bedrock and yellow indicates competent bedrock. 


\subsubsection{Site 5 Detailed Survey}

Unlike the large area surveys, the detailed survey was designed to sample the subsurface finely enough to allow kriging of the velocity surface. This allowed an animation of iso-velocity surfaces to be created for interpretation. The advantage is that this type of analysis favorably images continuous and coherent velocity surfaces. Figure 16 shows some screen shots of the iso-velocity surface animation of the detailed survey area. From top to bottom the images show, (a) the full velocity block from the beginning of the animation, (b) the removal of the overlying sediments, (c) a coherent underlying surface and (d) the incoherent velocity picture as noise dominates in the bottom of the section.

This analysis indicates the coherent surface comes in over a velocity range of 1.1 to $1.3 \mathrm{Km} / \mathrm{s}$. Like the larger survey results this velocity is too low for competent basalt but may represent the effect of vesicular basalt with an anomalously low velocity or a velocity surface, perhaps gravel, directly overlying and draping the basalts. Figure 17 shows the resulting top of basalt surface is fairly smooth over this scale dipping slightly to the northeast. There are smaller scale variations in the surface that are likely associated with small differences in the cross lines.

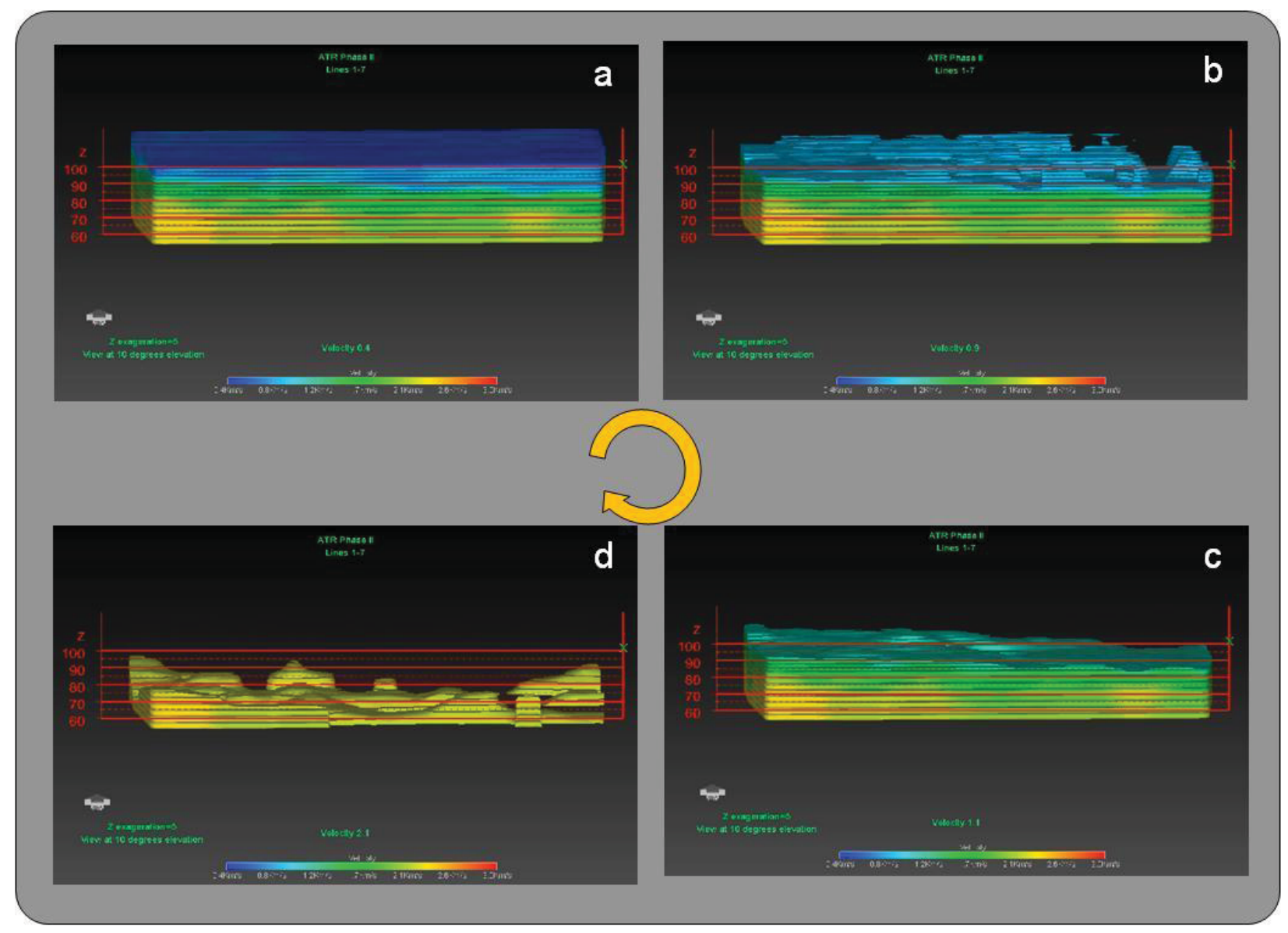

Figure 16. Site 5 detailed survey area results shown as screen captures of the iso-velocity surface animation. This process is used to identify the likely surface expression of layer boundaries and aid in interpretation of the results. This figure shows the complete velocity block with blue representing the slower velocities of the overlying sediments (a), the 'melting away' of the overlying sediments (b), revealing a coherent underlying surface (c), and an incoherent velocity picture as noise dominates in the bottom of the section (d). 


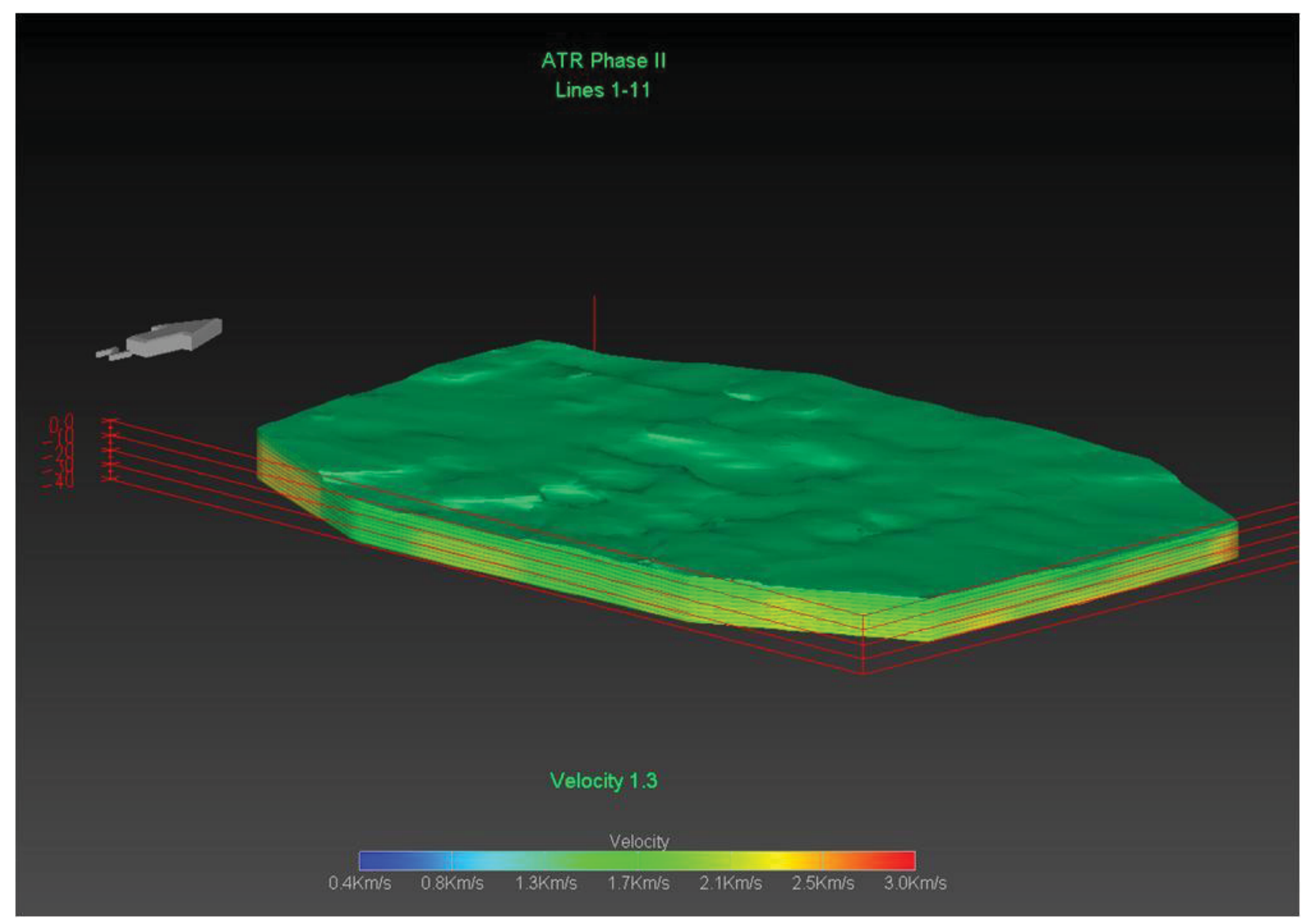

Figure 17. Site 5 detailed survey area representative of bedrock surface. This image shows a roughly flat surface that dips slightly to the northeast. Most of the smaller-scale variation in the surface seems to be associated with differences in the cross lines.

Finally, the interpreted sections are pulled from the kriged velocity block in the positions of the original seismic lines. These sections are interpreted three layer sections that show an upper soil layer (yellow, $\mathrm{V}<1.1 \mathrm{Km} / \mathrm{s}$ ), a transition zone (Gray, $\mathrm{V}=1.1-1.3 \mathrm{Km} / \mathrm{s}$ ), and interpreted bedrock (Blue, $\mathrm{V}>1.3$ $\mathrm{Km} / \mathrm{s})$. Figure 18 shows an example of these lines and individual lines are shown in Appendix A. 


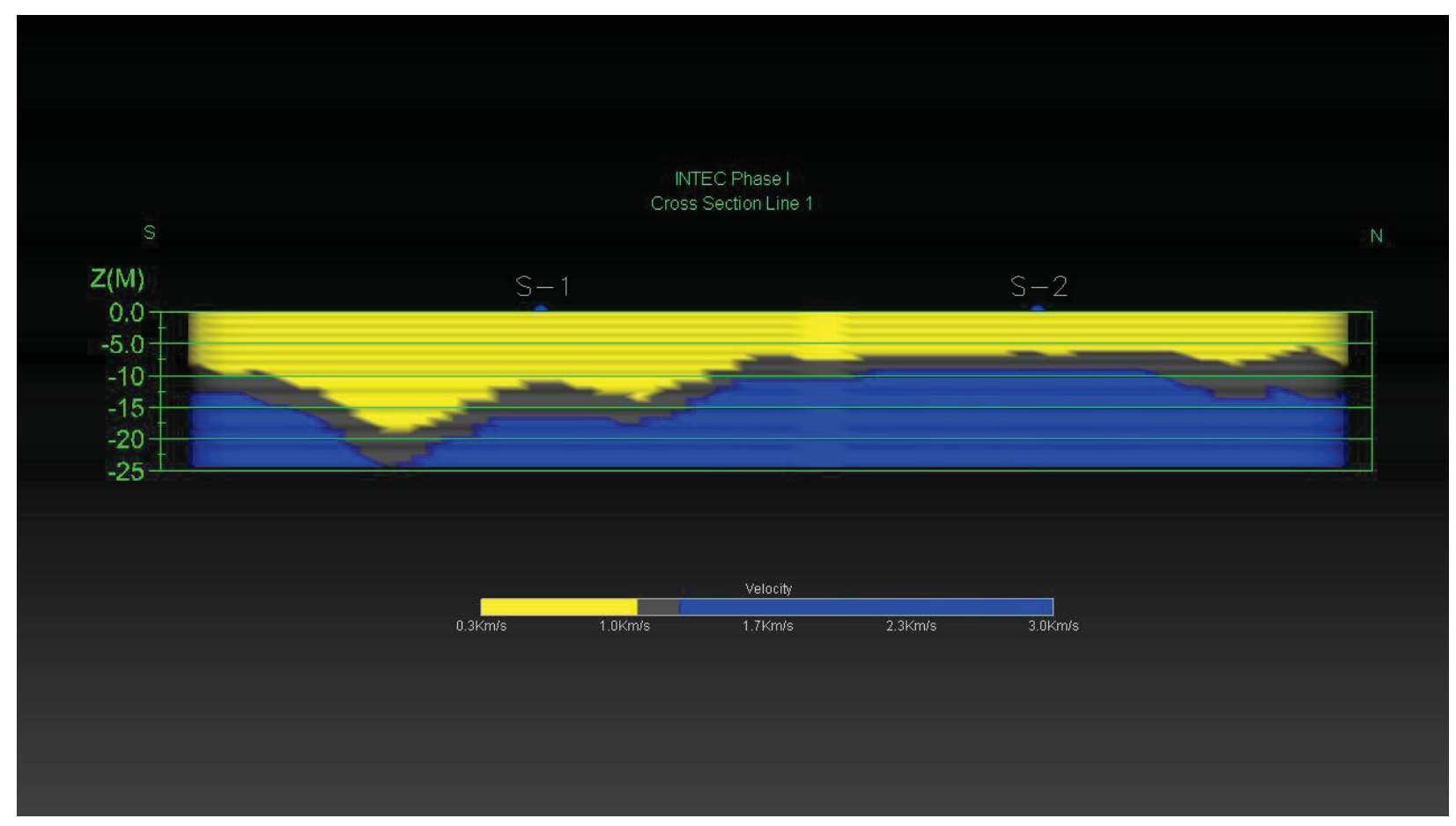

Figure 18. Site 34, line 1 acoustic velocity. Blue represents top of basalt, grey is an intermediate zone, and yellow represents the alluvium. The depth below land surface is indicated in meters.

\section{COMPARISONS OF SEISMIC RESULTS TO DRILLING DATA}

After the seismic surveys were completed, subsurface soil conditions were explored by drilling a total of 18 borings on Site 5 and Site 34. Twelve borings were drilled within the Site 5 area (Boring Nos. S- 07 through S-18). Six borings were drilled in the Site 34 area (Boring Nos. S-01 through S-06). The borings were advanced to practical refusal on basalt rock or resistant earth material. The approximate locations of the test borings are shown on Figures 19 and 20.

Limitations and data quality issues of the survey were introduced by:

- Depth: Resolution is reduced the farther from the sensors data is collected.

- Material: Geologic layers that are poorly consolidated will absorb most on the injected energy so that poor returns affect the signal to noise ratio.

- Strength of source: Unconsolidated material requires more energy for good data. To help overcome this it is possible to collect multiple hammer hits and stack the data.

- Data interpretation: Seismic data measures the density and consolidation of the materials so it can be difficult to determine if the response is from solid clay or some other type of rock. However, alluvium has a much different response from Basalt. The farther the interface is from the sensors the larger the differences need to be and the more the software will blend the transition zone.

- Line spacing: Spacing has a direct relationship with the resolution of the survey. Closer line spacing produces better results but is more costly.

- Noise: Noise from people, cars, wind, machinery etc. makes the data difficult to interpret and compromises the results. Noise from nearby vehicles on Lincoln Boulevard, and operations at INTEC resulted in more noise in the data at Site 34 
The drilling was accomplished with an all-terrain, track-mounted drill rig equipped with hollow stem augers for soil sampling. Soil samples were obtained using a standard and oversize split spoon sampler in general accordance with ASTM D 1586. Logs of the subsurface conditions, as encountered in the test borings, were recorded at the time of the field work by American Geotechnics (2011). Standard Penetration Test driving resistances for each six inch increment of penetration, or some distance thereof, are expressed as "SPT" N-values on the boring logs at the respective sampling depths.

Direct comparisons of bedrock depth were done at the borehole points and are summarized in Table 1. The column labeled "difference in meters" show the results. Negative numbers are locations that the seismic survey revealed bedrock was deeper that the drilling showed, and positive numbers are locations where the drilling results for bedrock are deeper than the seismic survey. The two methods had good correlation in most areas. Borehole S-07, for example, had only $1 \mathrm{~cm}$ difference which was the best match. The largest difference was $5.09 \mathrm{~m}$ at Borehole S-11.The area with the worst correlation was in the southwestern end of Site 5 around Boreholes S-10, S-11 and S-14 (see Figure 19). The drill samples were collected with a split spoon with at best five feet out of ten feet that were recovered which make a perfect one-to-one correlation difficult. A review of the drilling logs show S-09 has a clay layer at $30 \mathrm{ft}$ and a small sediment transition at $25 \mathrm{ft}$. The seismic energy could have refracted at either layer. If that occurred at the $25 \mathrm{ft}$ interface it would be an exact match, however it is more likely that the clay is the refractor as that has a much larger velocity change than what would be expected from the sediment change at $25 \mathrm{ft}$. Borehole S-10 also has an interface at $25 \mathrm{ft}$ and S-11 has one at $35 \mathrm{ft}$ which would match the seismic results. Site 34 Boreholes S-03, S-04 and S-06 were poor matches as shown in Figure 17. S-03 and S-04 show no possible refractors in the area that seismic data suggests there should be. This could be because the data on this line contained much more noise that the other lines due to ongoing work around the site, or that a small refracting layer was simply missed by the drilling and sampling method. The drillings logs reported a transition in Borehole S-06 at $11.5 \mathrm{~m}$ which is 0.5 meters different that the seismic survey showed a transition.

Table 1. A Comparison of basalt depth between borehole data and the seismic survey, data with negative numbers indicating deeper Basalt estimation in the seismic results than found while drilling.

\begin{tabular}{cccccc}
\hline Borehole & $\begin{array}{c}\text { Bottom } \\
\text { Material }\end{array}$ & $\begin{array}{c}\text { Borehole Basalt } \\
\text { Depth }(\mathrm{ft})\end{array}$ & $\begin{array}{c}\text { Borehole Basalt } \\
\text { Depth }(\mathrm{m})\end{array}$ & $\begin{array}{c}\text { Seismic Data } \\
\text { Basalt Depth }(\mathrm{m})\end{array}$ & $\begin{array}{c}\text { Depth } \\
\text { Difference }(\mathrm{m})\end{array}$ \\
\hline S-01 & basalt & 56.5 & 17.22 & 17.0 & 0.22 \\
S-02 & basalt & 31.0 & 9.45 & 9.0 & 0.45 \\
S-03 & basalt & 60.3 & 18.38 & 15.0 & 3.38 \\
S-04 & basalt & 45.0 & 13.72 & 10.5 & 3.22 \\
S-05 & no basalt & 35.1 & 10.70 & 12.5 & -1.80 \\
S-06 & basalt & 53.8 & 16.40 & 12.0 & 4.40 \\
S-07 & basalt & 29.5 & 8.99 & 9.0 & -0.01 \\
S-08 & basalt & 26.0 & 7.92 & 8.0 & -0.08 \\
S-09 & basalt & 31.8 & 9.69 & 7.5 & 2.19 \\
S-10 & basalt & 39.8 & 12.13 & 7.5 & 4.63 \\
S-11 & basalt & 49.5 & 15.09 & 10.0 & 5.09 \\
S-12 & basalt & 50.8 & 15.48 & 15.0 & 0.48 \\
S-13 & basalt & 40.2 & 12.25 & 10.0 & 2.25 \\
S-14 & basalt & 45.5 & 13.87 & 10.0 & 3.87 \\
S-15 & basalt & 44.5 & 13.56 & 12.0 & 1.56 \\
S-16 & basalt & 39.5 & 12.04 & NA & NA \\
S-17 & basalt & 48.0 & 14.63 & NA & NA \\
S-18 & basalt & 45.5 & 13.87 & NA & NA \\
\hline
\end{tabular}

NA $=$ Not Applicable. Boreholes S-16, S-17 and S18 not located close enough to a survey line for comparison. 


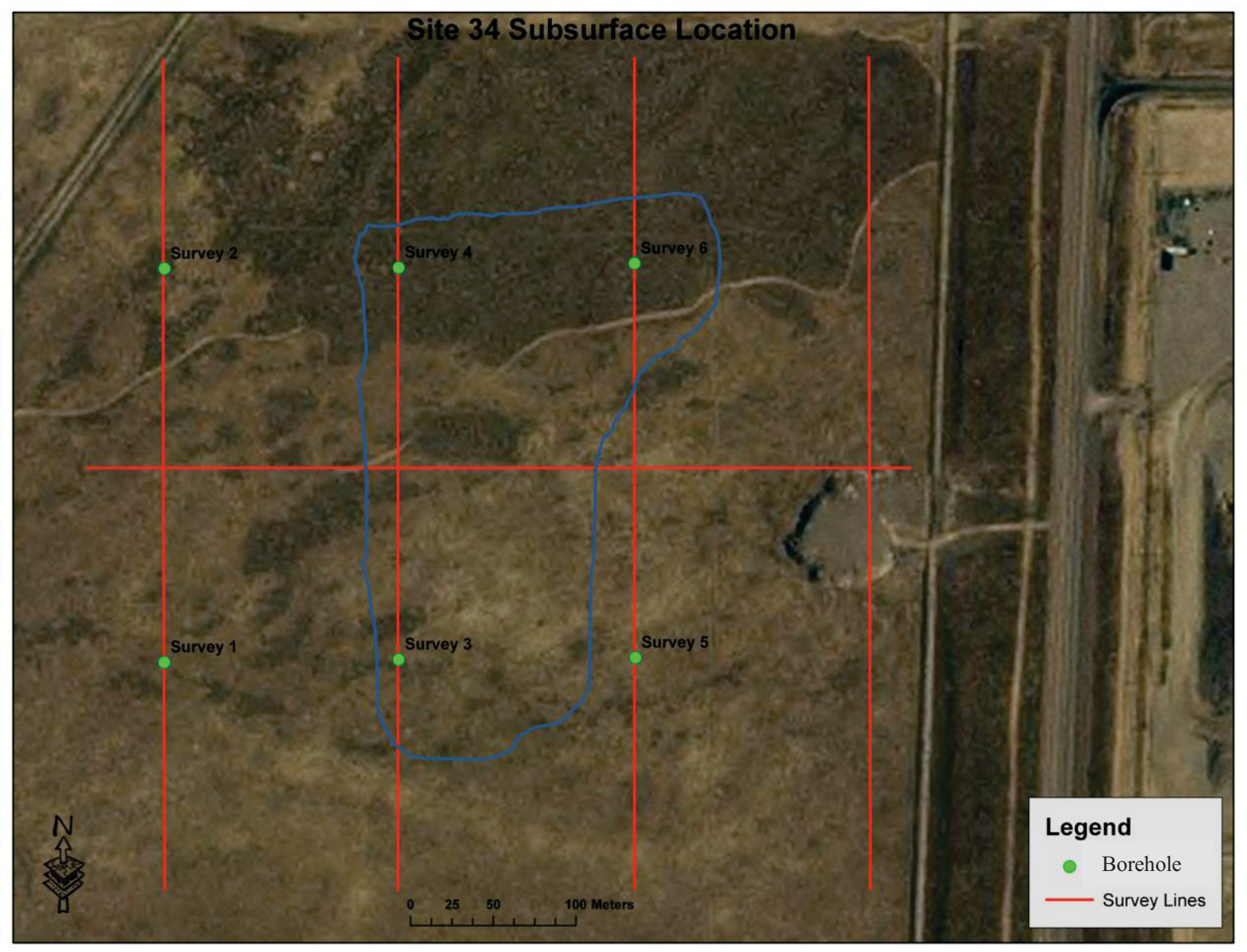

Figure 19. Site 34 borehole locations. The boreholes within the blue line are locations with a mismatch between the interpretation of the seismic data and borehole data of more than 3 meters. Line 2 had noisy data on this line and this was most likely a contributing factor to the mismatch at Boreholes S-03 and S04. 


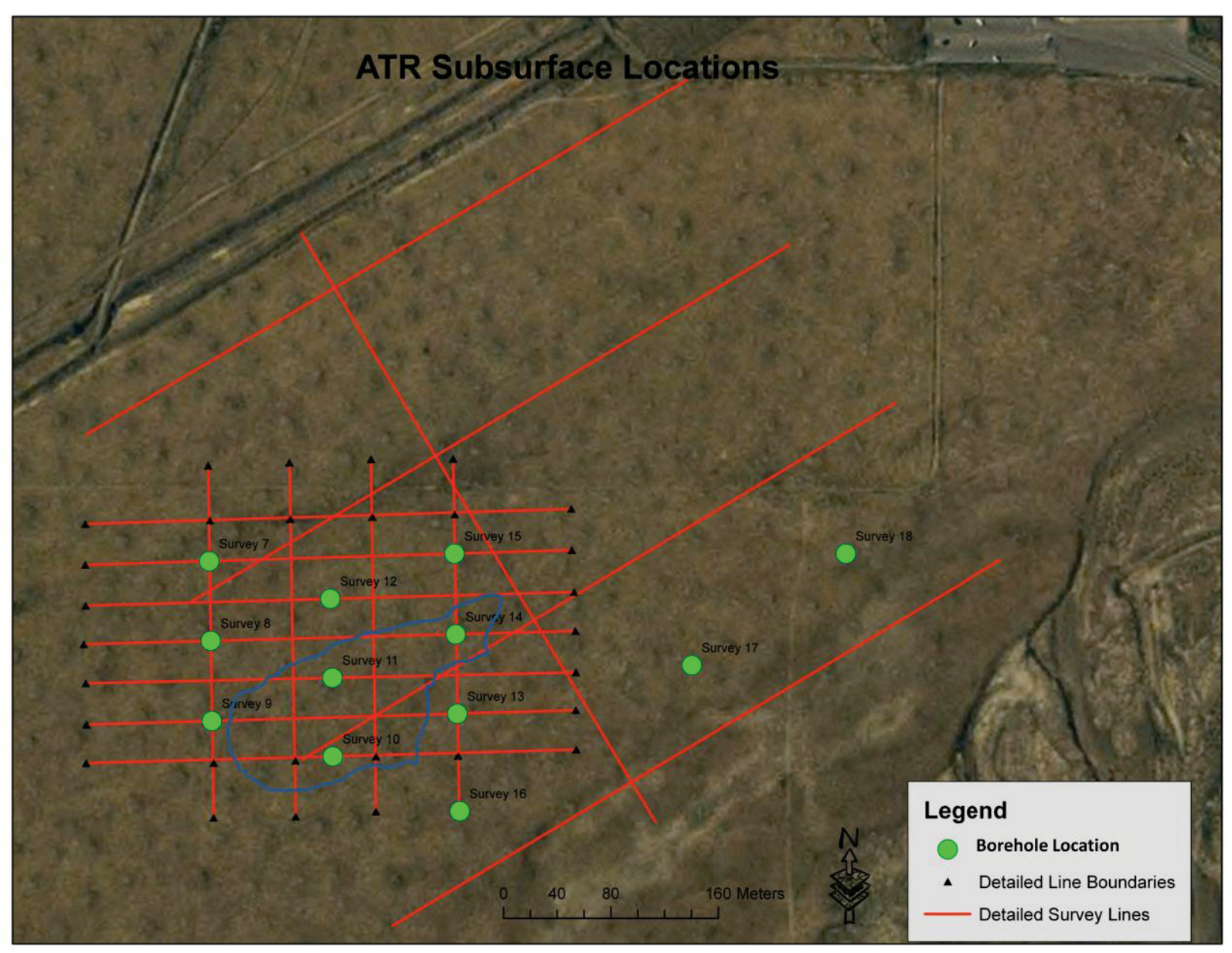

Figure 20. Site 5 borehole locations. The boreholes within the blue line are locations with a mismatch between the seismic data and borehole data of more than 3 meters. The areas of mismatch at this location are most likely a refracting layer above the basalt that could be a clay layer.

\section{SUMMARY}

Seismic refraction data were collected and processed to image the depth to basalt at two sites being considered for the INL RH-LLW disposal facility. Large-scale surveys were conducted at both sites and the data used to construct two-dimensional fence diagrams along the survey lines. A more detailed survey was conducted at Site 5 in an area where the basalt surface appeared the deepest. A threedimensional surface of the basalt was constructed from the data in the detailed survey area.

Seismic survey results show the depth to basalt ranges from 8 to $15.5 \mathrm{~m}$ at Site 5 , and from 9 to $18 \mathrm{~m}$ at Site 34. Basalt depths from survey data were compared directly to data from drilling performed after the surveys were complete. The differences ranged from $0.01 \mathrm{~m}$ to $5.09 \mathrm{~m}$ with an average difference of about $2 \mathrm{~m}$. In most cases, the seismic data underestimated the depth to basalt. This is likely due to the presence of dense refracting layers (basalt lenses or clay), or material transitions above the basalt surface that make data interpretation more difficult.

In general, the variability in basalt depth at Site 5 is less than that at Site 34. Confidence in the results at Site 5 is greater than at Site 34 because of the smaller-scale detailed survey at Site 5 and poorer data quality in general at Site 34. The data on all lines at Site 34 were reasonable, but certainly influenced by 
vehicle noise on nearby Lincoln Boulevard and operations noise at the ICDF and INTEC facilities. Data on line 2 at Site 34 was particularly noisy.

\section{REFERENCES}

American Geotechnics, 2011, Geotechnical Investigation Proposed RHLLW Facility, Butte County, Idaho, File No. 10B-G2163, prepared for Battelle Energy Alliance by American Geotechnics.

INL, 2011, Conceptual Design Report for the Remote-Handled Low-Level Waste Disposal Facility, INL/EXT-07-12901, Revision 5, Idaho National Laboratory, May 2011. 


\section{Appendix A \\ Velocity Cross Sections \\ Interpretation of the Seismic Data}




\section{Appendix A}

\section{A-1. INTRODUCTION}

This appendix presents the individual interpreted sections extracted from the kriged velocity volume for Site 34 and Site 5. The positions for these interpreted sections correspond to those of the original seismic lines. These sections show the three-layer interpretation with an upper soil layer (yellow, $\mathrm{V}<1.1$ $\mathrm{Km} / \mathrm{s}$ ), a transition zone (Gray, $\mathrm{V}=1.1-1.3 \mathrm{Km} / \mathrm{s}$ ), and interpreted bedrock (Blue, $\mathrm{V}>1.3 \mathrm{Km} / \mathrm{s}$ ). Positions for these sections are given in Figures 5 and 6 of the main report.

\section{A-2. SITE 34 INDIVIDUAL VELOCITY CROSS SECTIONS}

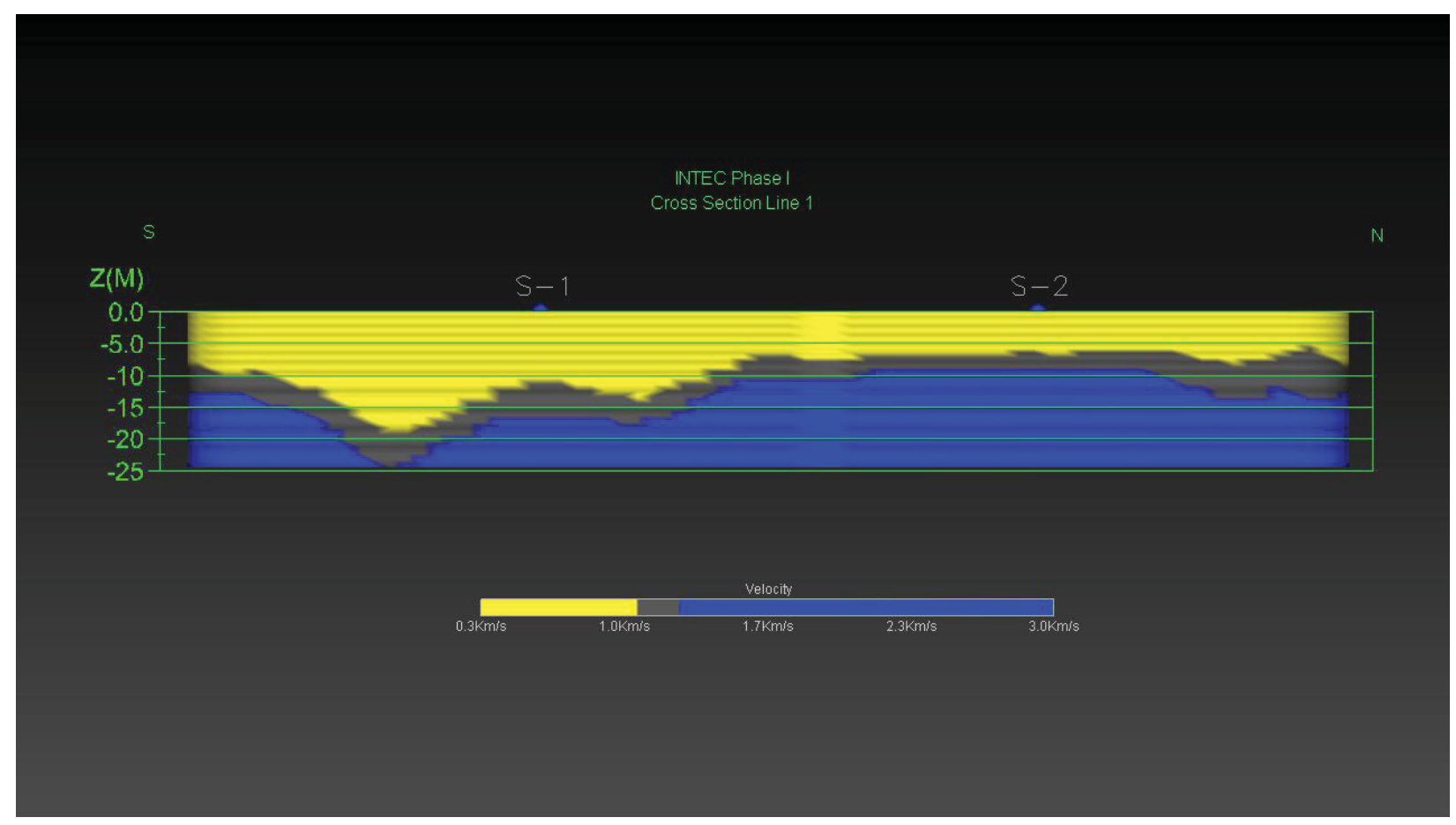

Figure A-1. Site 34, line 1 acoustic velocity. Blue represents top of basalt, grey is an intermediate zone, and yellow represents the alluvium. The depth (ZM) below land surface is indicated in meters. 


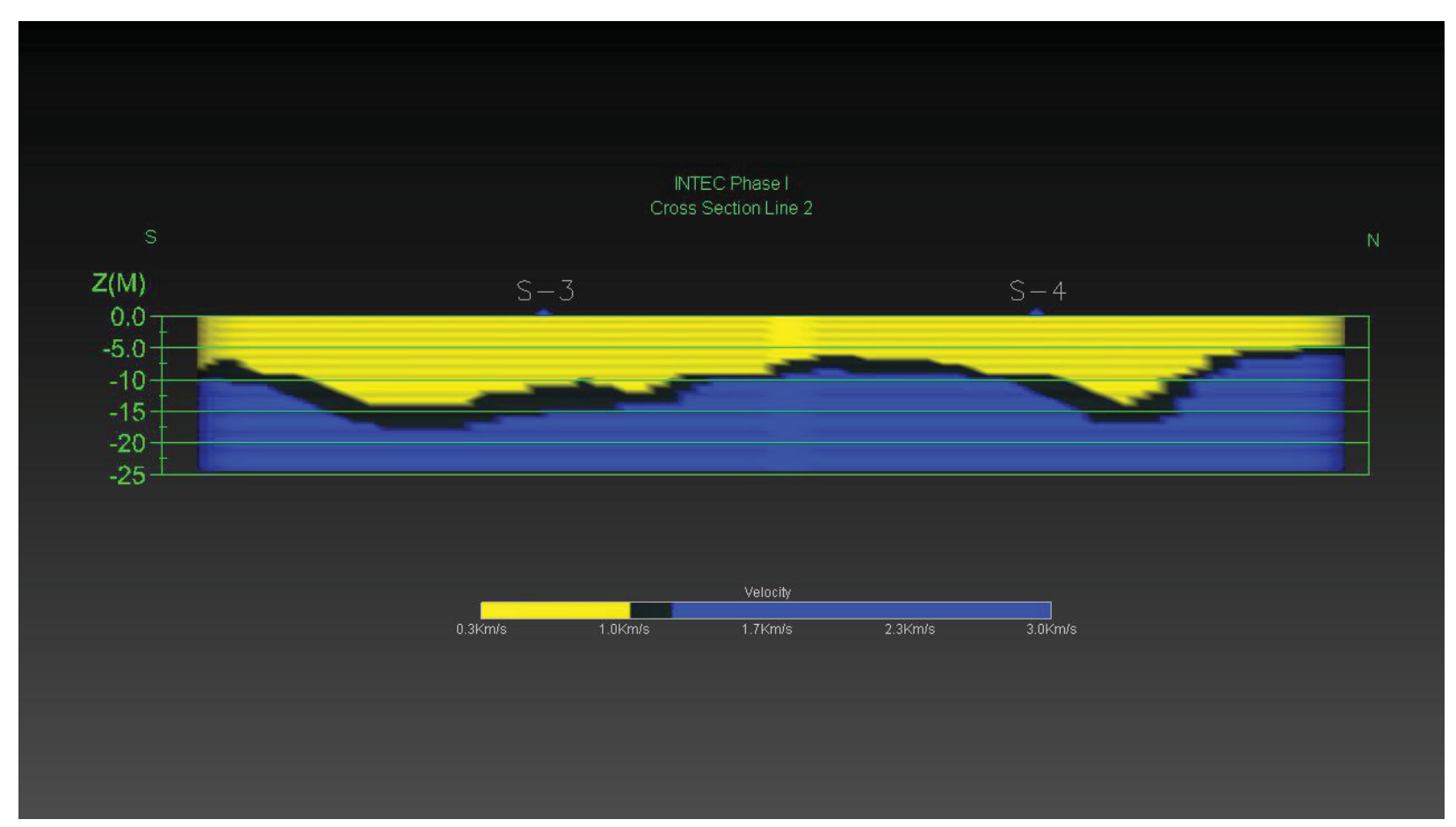

Figure A-2. Site 34, line 2 acoustic velocity. Blue represents top of basalt, grey is an intermediate zone, and yellow represents the alluvium. The depth below land surface is indicated in meters.

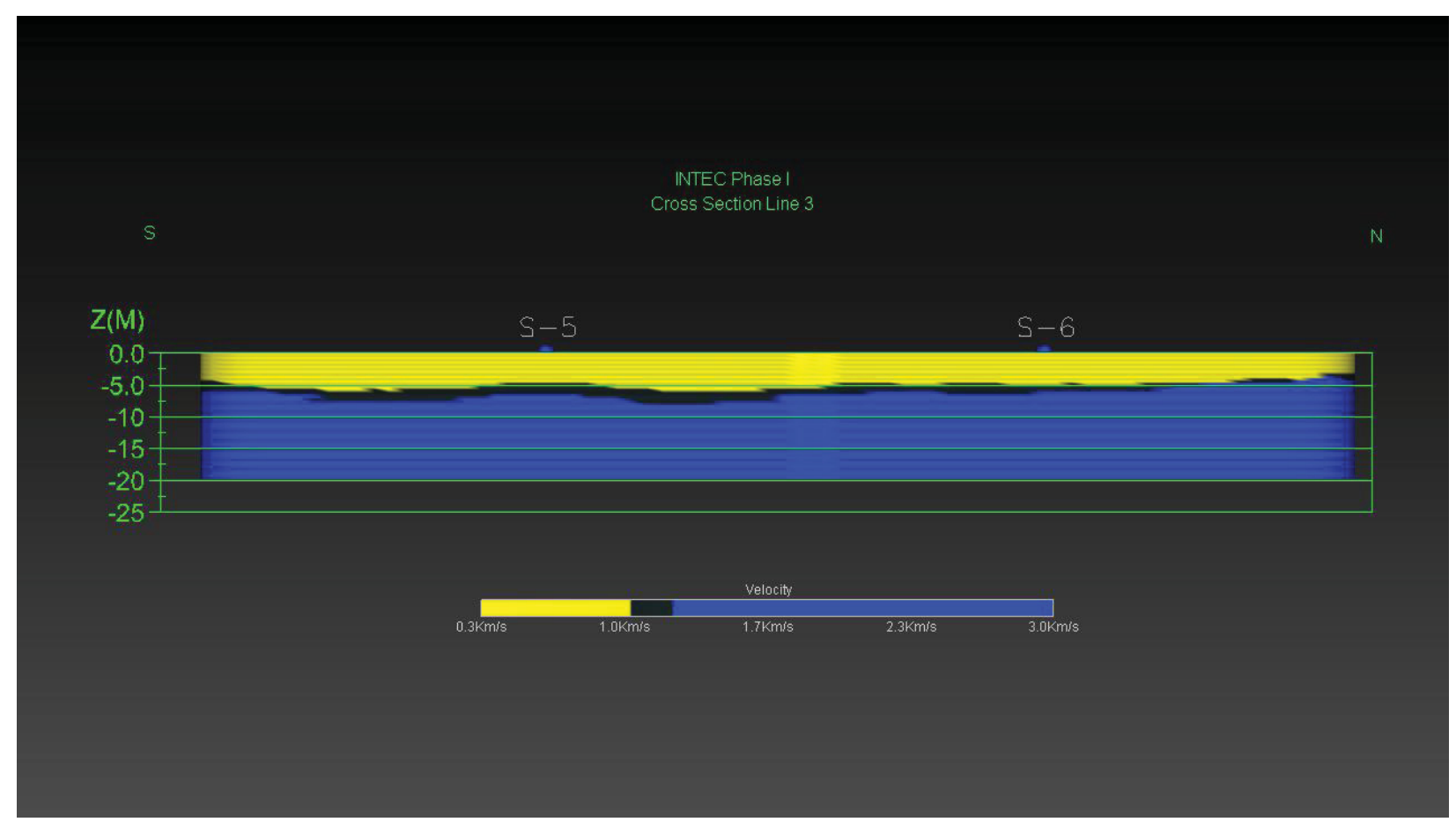

Figure A-3. Site 34, line 3 acoustic velocity. Blue represents top of basalt, grey is an intermediate zone, and yellow represents the alluvium. The depth below land surface is indicated in meters. 
$-10$

$-15$

$-20$

$-25$

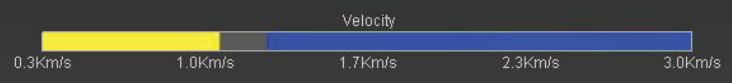

Figure A-4. Site 34, line 4 acoustic velocity. Blue represents top of basalt, grey is an intermediate zone, and yellow represents the alluvium. The depth below land surface is indicated in meters.

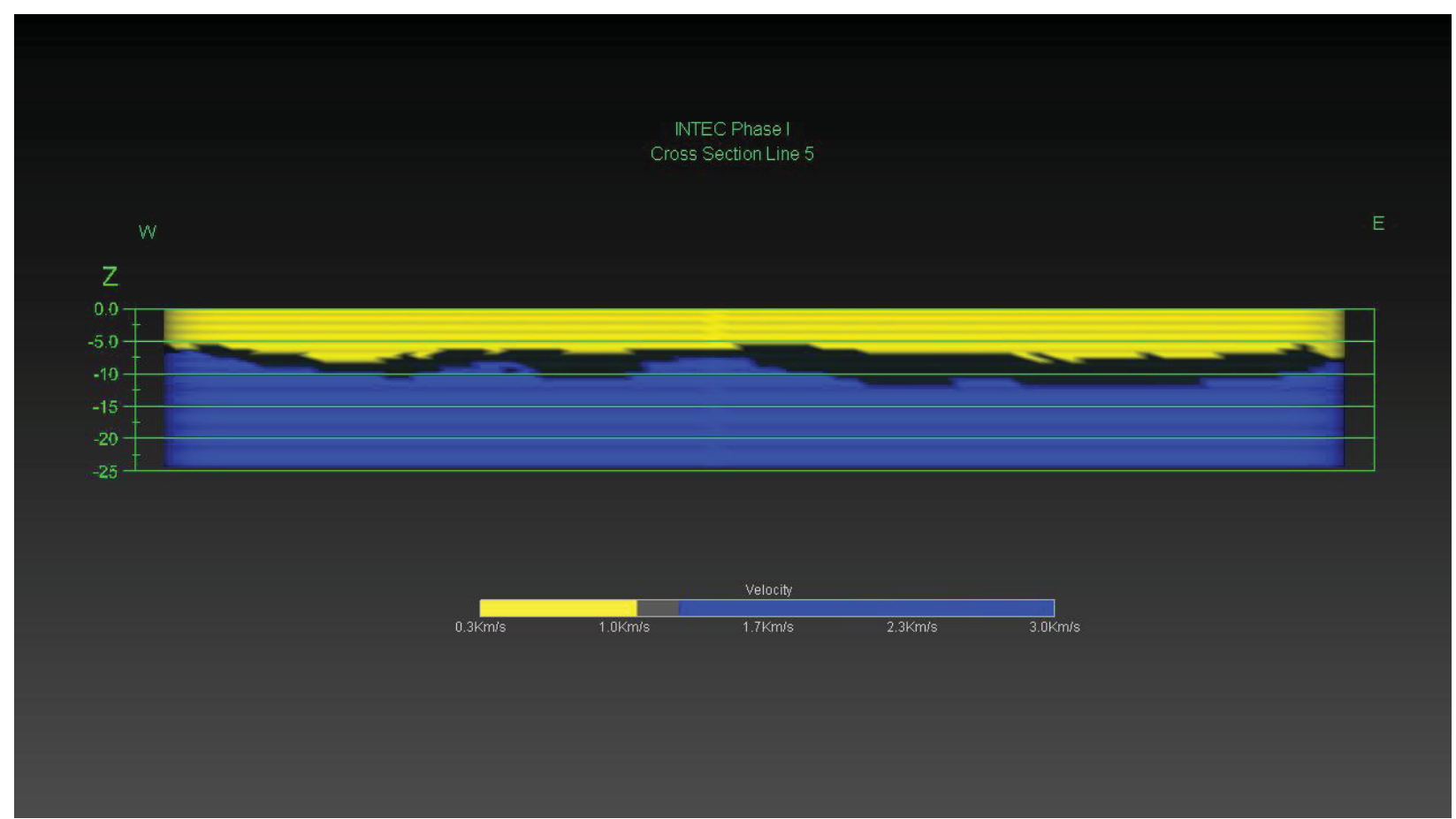

Figure A-5. Site 34, line 5 acoustic velocity. Blue represents top of basalt, grey is an intermediate zone, and yellow represents the alluvium. The depth below land surface is indicated in meters. 


\section{A-3. SITE 5: INDIVIDUAL VELOCITY CROSS SECTIONS}

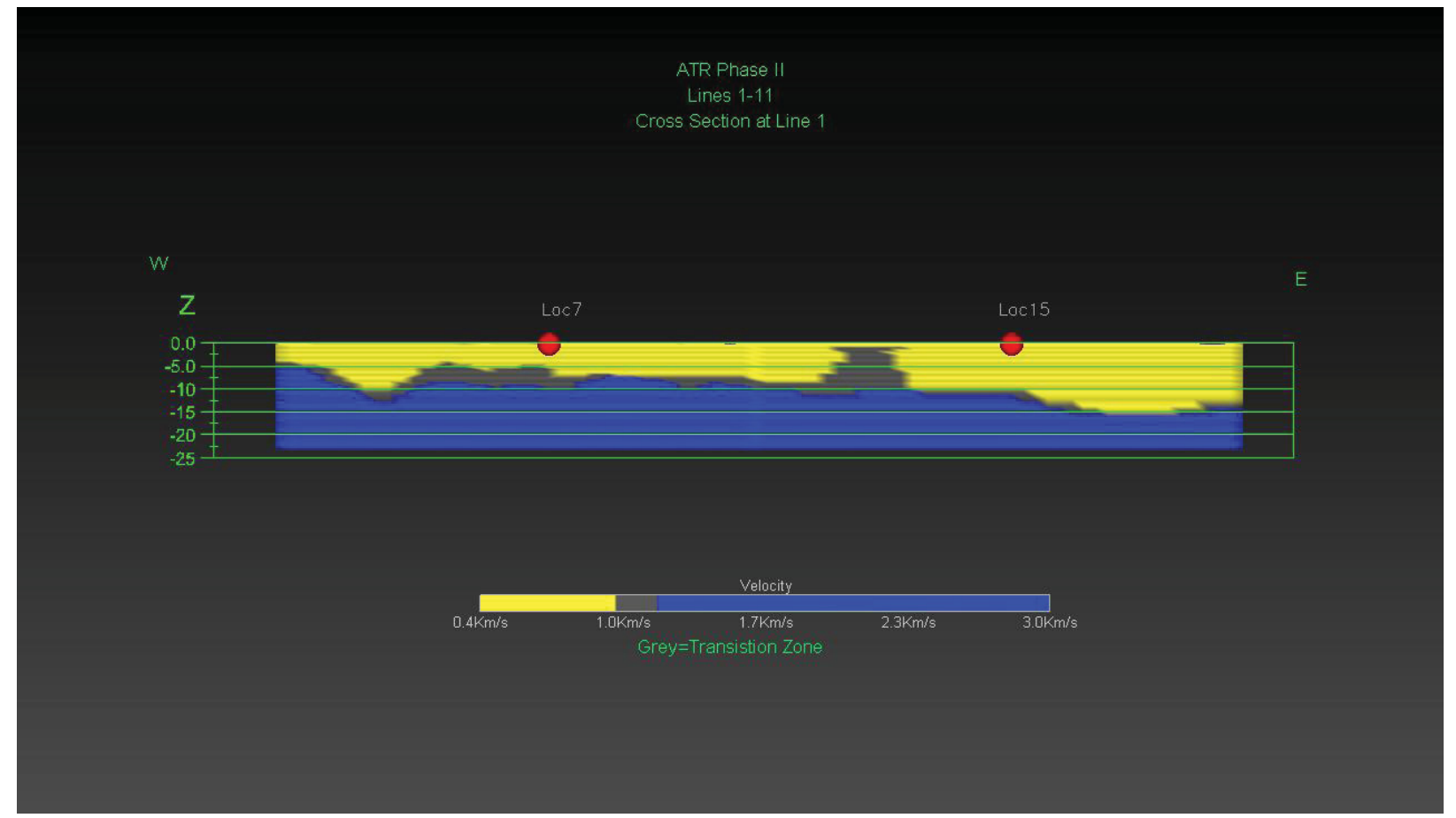

Figure A-6. Site 5, line 1 acoustic velocity. Blue represents top of basalt, grey is an intermediate zone, and yellow represents the alluvium. The depth below land surface is indicated in meters.

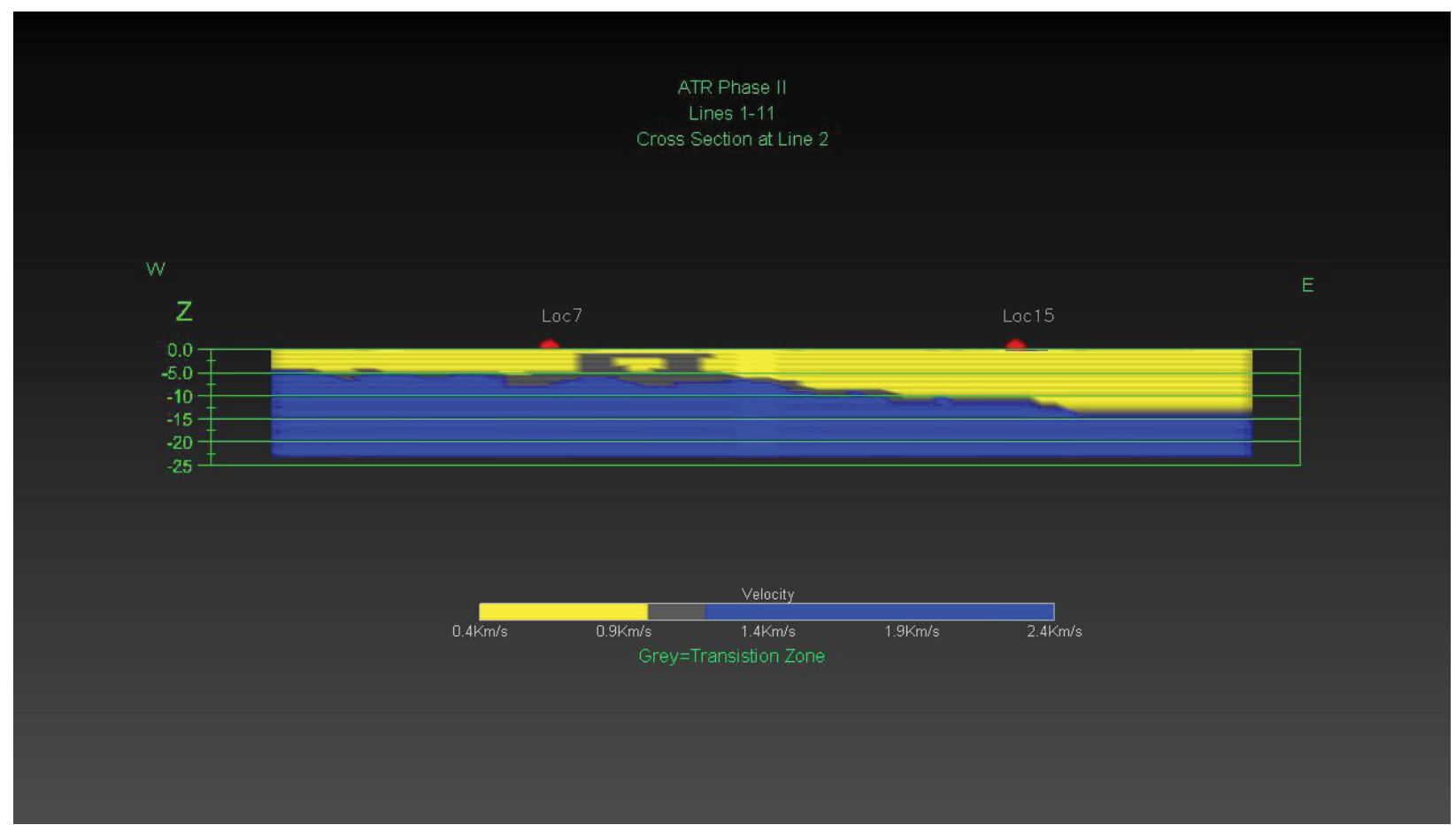

Figure A-7. Site 5, line 2 acoustic velocity. Blue represents top of basalt, grey is an intermediate zone, and yellow represents the alluvium. The depth below land surface is indicated in meters. 


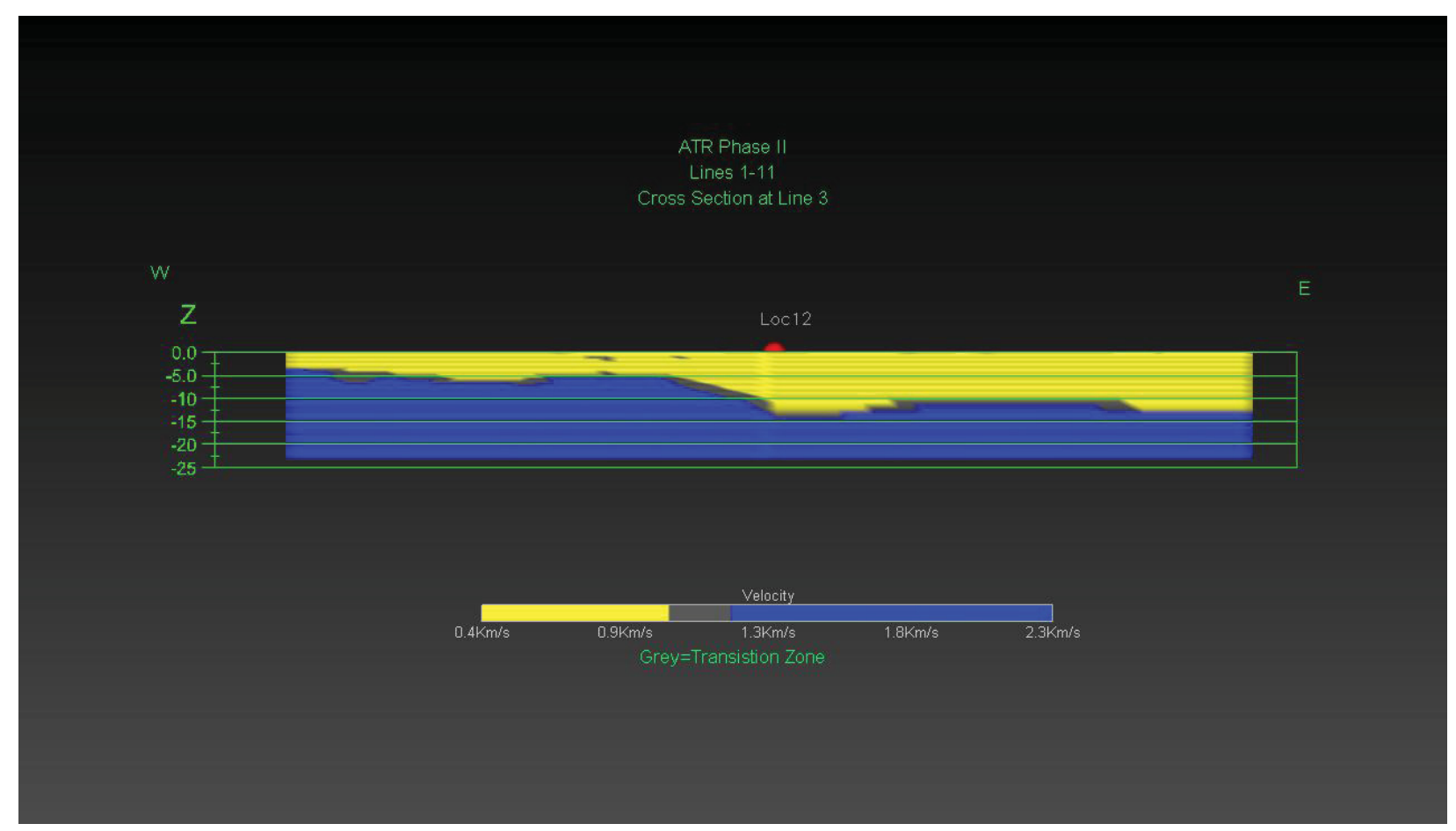

Figure A-8. Site 5, line 3 acoustic velocity. Blue represents top of basalt, grey is an intermediate zone, and yellow represents the alluvium. The depth below land surface is indicated in meters.

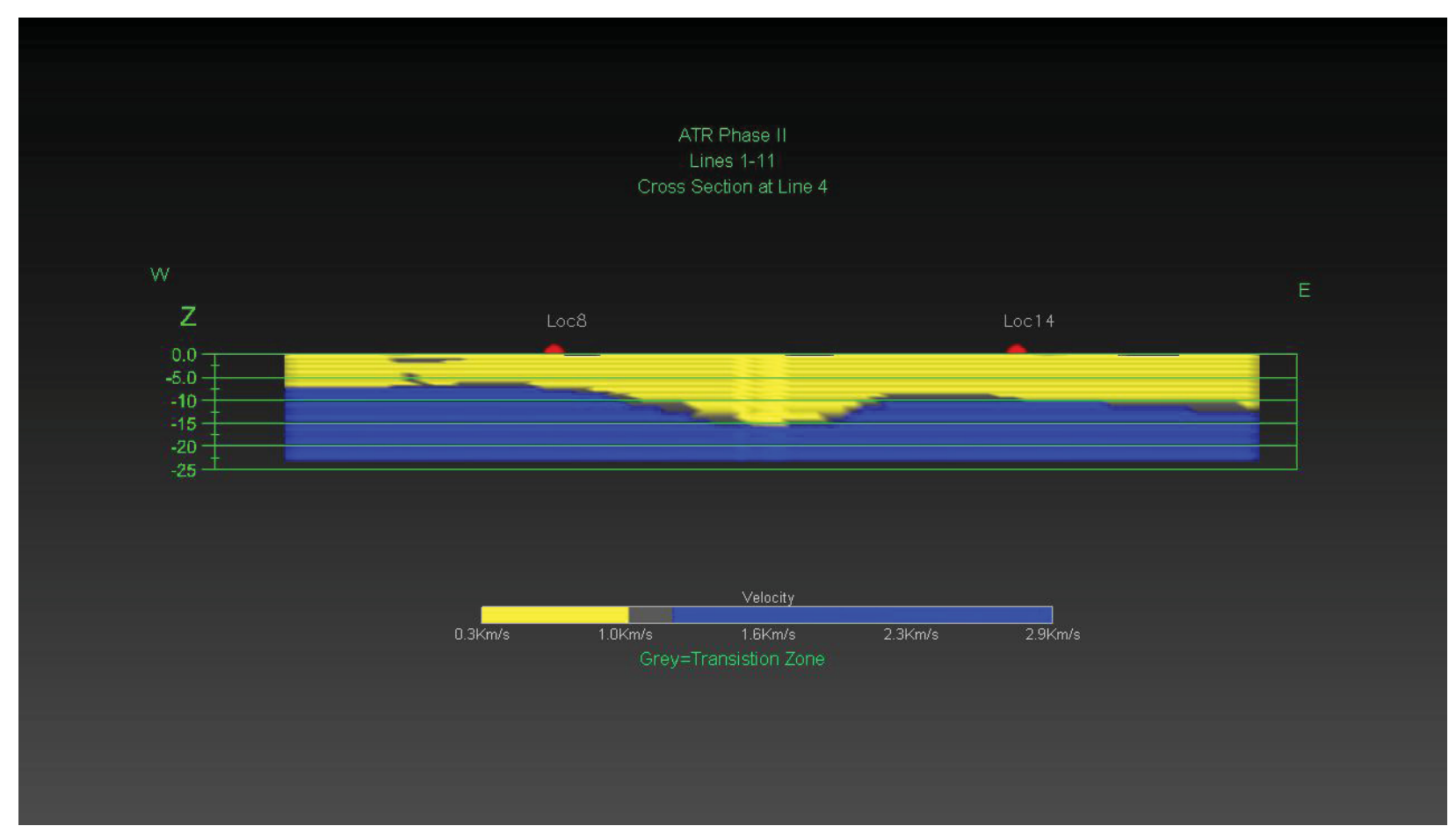

Figure A-9 Site 5, line 4 acoustic velocity. Blue represents top of basalt, grey is an intermediate zone, and yellow represents the alluvium. The depth below land surface is indicated in meters. 


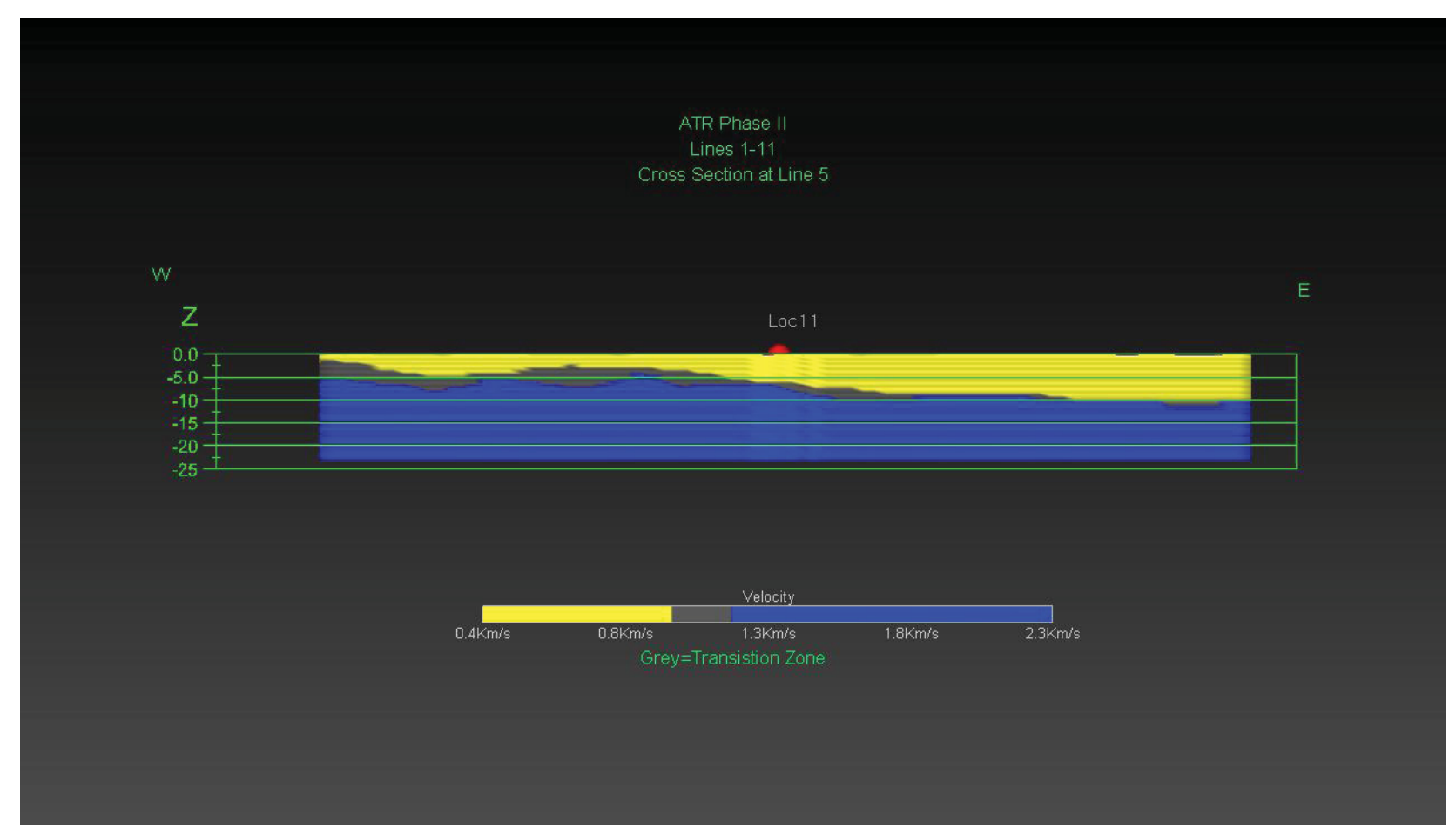

Figure A-10. Site 5, line 5 acoustic velocity. Blue represents top of basalt, grey is an intermediate zone, and yellow represents the alluvium. The depth below land surface $(Z)$ is indicated in meters.

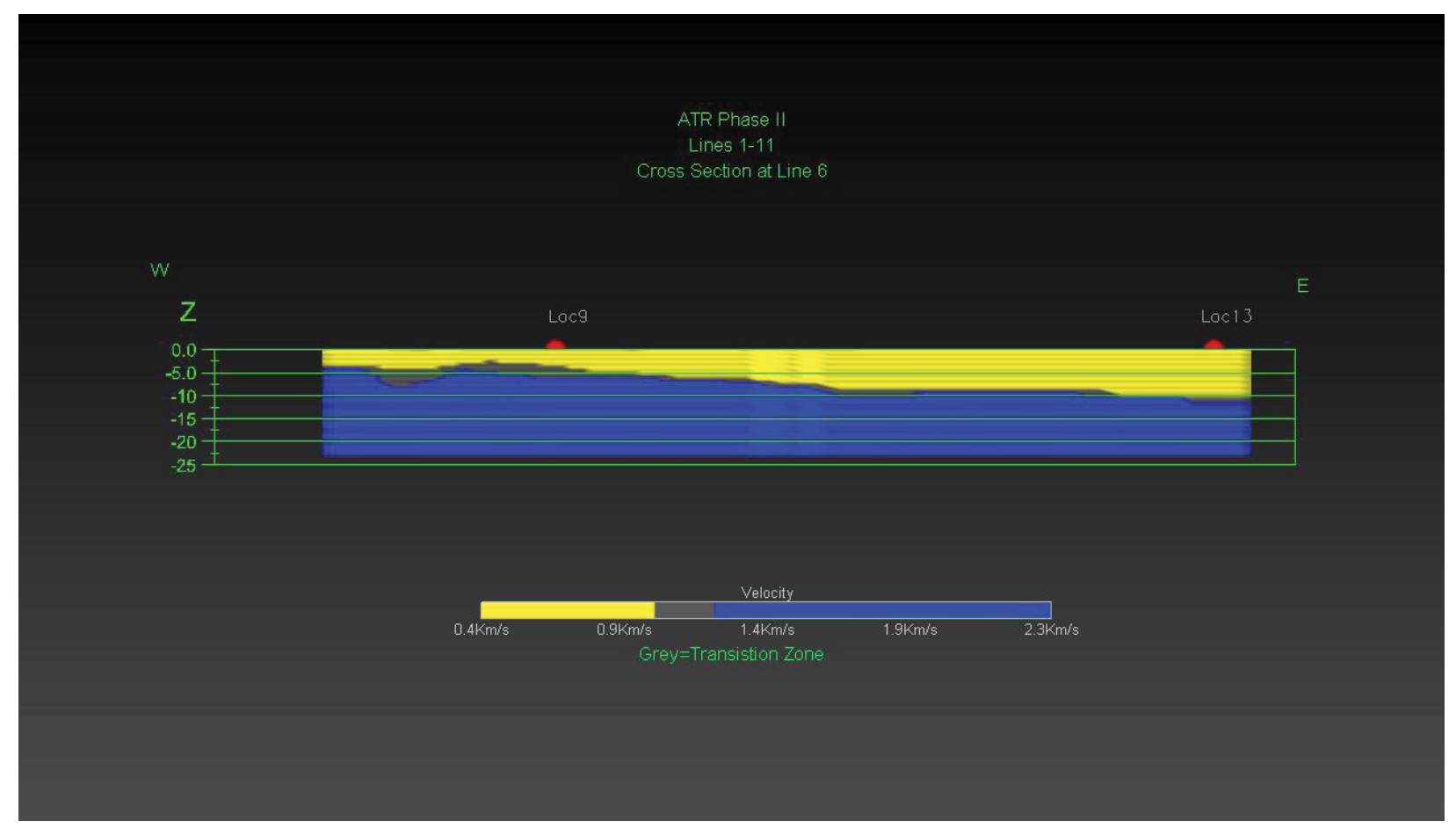

Figure A-11. Site 5, line 6 acoustic velocity. Blue represents top of basalt, grey is an intermediate zone, and yellow represents the alluvium. The depth below land surface is indicated in meters. 


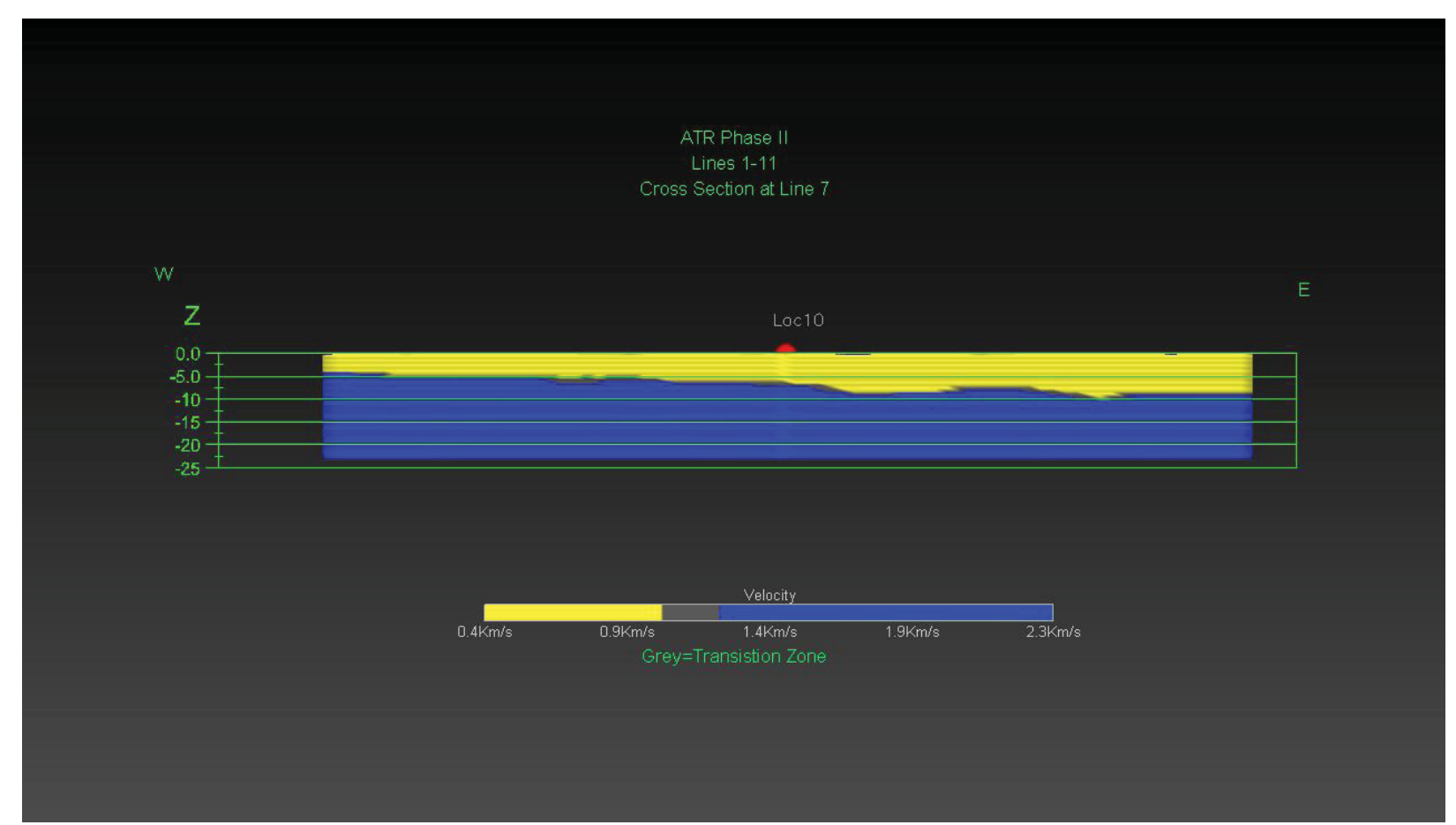

Figure A-12. Site 5, line 7 acoustic velocity. Blue represents top of basalt, grey is an intermediate zone, and yellow represents the alluvium. The depth below land surface is indicated in meters. 